The Wage-Productivity Nexus in the World Factory Economy

Giovanni Dosi, Maria Enrica Virgillito, and Xiaodan Yu

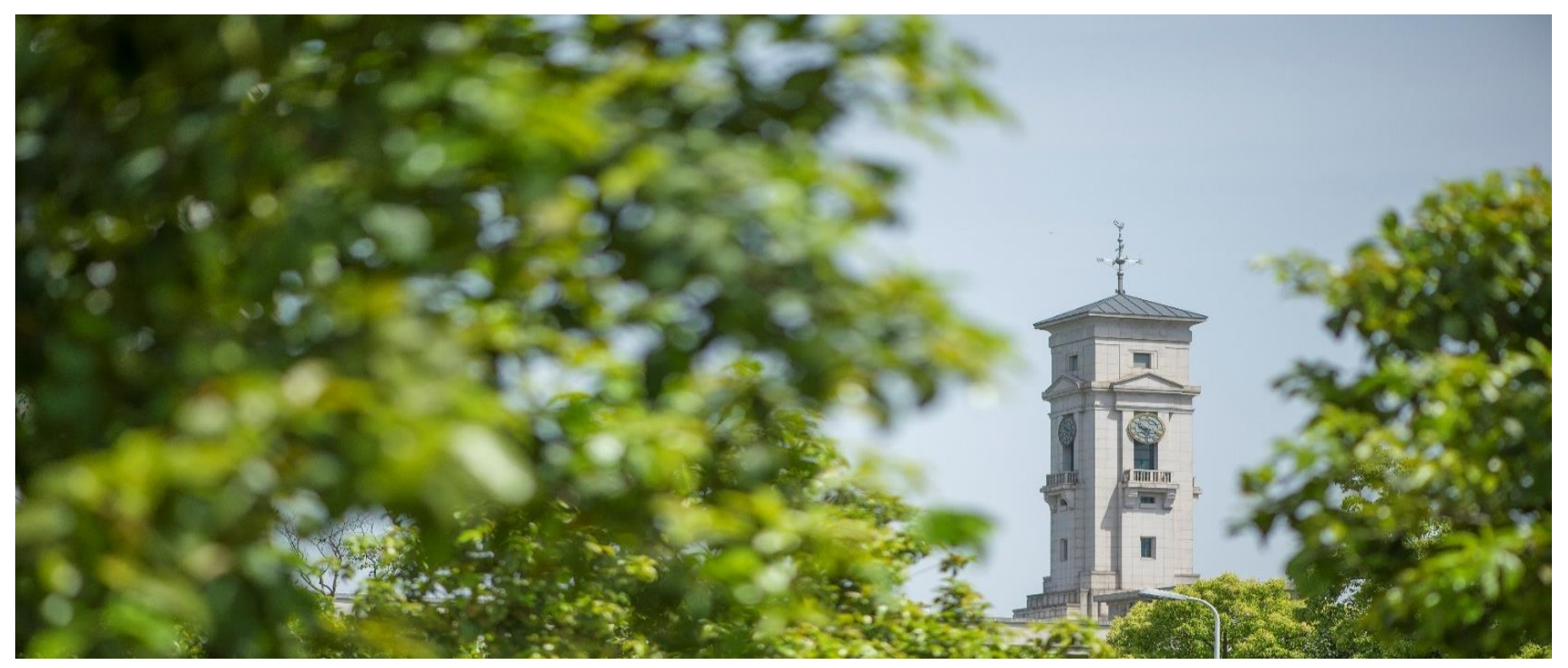


Faculty of Business, University of Nottingham Ningbo China, 199 Taikang East Road, Ningbo, 315100, Zhejiang, China.

First published 2020

This work is made available under the terms of the Creative Commons Attribution 4.0 International License:

http://creativecommons.org/licenses/by/4.0

The work is licenced to the University of Nottingham Ningbo China under the Global University Publication Licence:

https://www.nottingham.edu.cn/en/library/documents/researchsupport/global-university-publications-licence.pdf 


\title{
The Wage-Productivity Nexus in the World Factory Economy
}

\author{
Giovanni Dosi ${ }^{* \dagger}$, Maria Enrica Virgillito ${ }^{\ddagger \dagger}$, and Xiaodan $\mathrm{Yu}^{\dagger, \pi}$ \\ †Institute of Economics, Scuola Superiore Sant'Anna, Pisa, Italy \\ ${ }^{\ddagger}$ Department of Economic Policy, Universita’ Cattolica del Sacro Cuore, Milan, Italy \\ `Nottingham University Business School China, University of Nottingham Ningbo, China
}

\begin{abstract}
This paper highlights new findings on the wage-productivity nexus in the World Factory Economy. After presenting the long-run macro-elasticity characterizing the phase of Chinese economic development since the eighties, we look at the wage-productivity nexus from a micro level perspective using a detailed firm-level dataset covering the period of ownership restructuring (1998-2007). A few results are quite robust under different estimation strategies. First, throughout the impressive Chinese economic miracle, elasticities of real wages to productivities - that is the ratios of rates of variations of the former to the latter - are always positive both under pooled and longitudinal estimates, both at firm- and sectoral-levels. Second, such elasticities are dramatically low, and falling in many distinct phases since the late seventies. That is, even in the manufacturing sector, the distribution of gains from the impressive labour productivity growth appears to be markedly uneven. Finally, third, governance institutions seem to matter a lot, with the majority of ownership types exhibiting firm-specific wage determination processes. The low elasticities of wages to productivity are plausibly the consequence of the massive flow of migrant workers from the rural areas to the coasts, somewhat resembling the early phase of the English Industrial Revolution with the pattern of enclosure in the country-side and massive migrations to the industrial towns.
\end{abstract}

JEL codes: L6, D22, D24, J31

Keywords: Chinese Industrialization, Gain-sharing, Labour market institutions, Labour productivity, Wage dispersion

*Corresponding author: Institute of Economics, Scuola Superiore Sant'Anna, Piazza Martiri della Liberta' 33, I-56127, Pisa (Italy). E-mail address: gdosi<at>santannapisa.it 


\section{Introduction}

This work studies the microeconomic dynamics of wages and productivity, and their relationship in Chinese manufacturing firms over the decade preceding the Great Recession. As known, increasing evidence suggests that in the industrialized West labour productivity has slowed down (Syverson, 2017), while its dispersion has increased (Dunne et al., 2004). As so did wages, which in some countries like U.S. remained nearly stagnant on average, but under increasing degrees of dispersion (Barth et al., 2016). OECD supporting findings on the double divide are in Berlingieri et al. (2017), especially for the service sector and especially concerning the bottom-part of the distributions of wage and productivity (50 - 10 percentiles). In fact, in the "glorious decade" after WWII in the industrialized West, wages were fully indexed on productivity, often at sectoral or even national levels. However, more recently such indexation (so called degree of "pass-through") has generally fallen and moved to the firm-level (Schwellnus et al., 2017). Confirmatory evidence for the U.S. is reported by Stansbury and Summers (2017) who find elasticities ranging between [0.4 - 0.7] according to estimations based on average, median and production-non supervisory wages, with the latter having the lowest degree of pass-through. In UK as well the median wage has suffered more from the wedge than the average wage (Pessoa and Van Reenen, 2013). In a complementary analysis, Card et al. (2018) show very low elasticities even at the micro-level. Structural causes such as the increasing flexibility of labour markets (Mergulhão and Pereira, 2019, with a firm-level analysis for Portugal), the widening gap between median and average wage and the declining labour share are considered the best candidates to explain such divergences, more than the purported impact exerted by technological change. To the best of our knowledge, evidence on developing countries is very scant, exceptions being Bhattacharya et al. (2011) for Indian manufacturing firms, which however look at the effects of wages on labour productivity; Wakeford (2004) for South Africa and Katovich and Maia (2018) for Brazil. According to the latter studies, the elasticity in developing countries appears to be consistently lower than the one reported for developed ones, in the range between $[0.1-0.3]$.

What happened in China? Here, against the foregoing tendencies, we shall examine the characteristics of the wage-productivity nexus in the World Factory Economy. While the patterns of productivity growth and convergence for the Chinese manufacturing sectors have been addressed in the literature (see, among others, Author A), less attention has been devoted to the analysis of the distribution of the latter impressive technological gains to wages. This is precisely what we shall do in the following. Using a detailed firm-level dataset which includes all industrial firms above some minimal scale threshold over the period 1998-2007, distinguishing also the ownership types of the firms (e.g., State-owned, foreign MNCs, private-owned, etc.), we investigate the inter-sectoral and interinstitutional heterogeneity in both wage and productivity distributions and the coupled dynamics of the two latter variables, both in level and growth rates.

First of all we document an overall process of convergence in both variables, even if more marked in productivity, and above all driven by the bottom part of the distributions (50-10 percentile ratio). When decomposing variance in terms of within and between sectoral variations, in both cases the within-sectoral (between-firms) component accounts for more than $80 \%$ of the total variation. In that, however, while the dispersion in productivity shrinks, the wage one remains nearly stable during the period under study.

In order to explore the link between wage and productivity we perform quantile regression esti- 
mates in levels and growth rates for the mean, as well as for the second moment. Interestingly, the relationship between wage and productivity substantially varies conditional on the ownership type, with Hong Kong/Macao/Taiwan-invested enterprises (HMTs), foreign-invested enterprises (FIEs), and domestic private owned enterprises (POEs), positively contributing to an increasing wage dispersion, while State-owned enterprises (SOEs) help in its reduction. However, what is remarkable are the low coefficients of elasticities, both in absolute and in relative terms, when compared to the Western findings, which are always below 0.35 , and often in the neighbourhood of 0.15 . That is to say, most of the fruits of the impressive technological catching-up have not been passed through wages. When looking at growth rates, such elasticities vary across the quantiles of the wage growth distributions according to a U-shaped relation, ${ }^{1}$ with the lowest and highest wage growth quantiles having relatively higher pass-through degrees.

In order to exploit the time structure of the dataset while preserving the quantile regression approach, we also perform both a correlated random and a fixed effects quantile estimation. The estimated dynamic panel quantile regressions do confirm the different role played by SOEs vis-à-vis private ones, with only the former exerting an equalizing role. Overall, our results suggest the continuing coexistence of two processes of wage determination, distinct in terms of their degrees of idiosyncratic market responsiveness.

Finally, with respect to the wage-productivity variance relationship we find a positive monotonic link: hence sectors characterized by a less dispersed distribution in productivities display also relatively more equal wage distributions.

The paper is organized as follows: Section 2 briefly discusses the institutional transformations and some ensuing effects, while Section 3 presents the data structure together with some descriptive evidence on the coupled dynamics between wage and productivity. In Section 4 we perform a shift-and-share decomposition of wage and productivity dispersions to detect the different sources of heterogeneity. Section 5 addresses the firm-level link between wage and productivity by means of quantile regressions, both pooled and longitudinal. Finally, Section 6 provides some theoretical interpretations and Section 7 concludes our analysis.

\section{The institutional transformations: the broad picture}

Let us start by placing the dynamics of wage and productivity in the broader context of the institutional and structural transformations which China underwent. During the period 1998-2007 there are at least three remarkable institutional changes that might have influenced the relationship between wage and productivity, namely the process of restructuring of SOEs, the adherence to the WTO, and finally the introduction of the minimum wage. Together, as analysed in Author A, China undertook an impressive process of catching-up, characterised by a dramatic growth in labour productivity. The latter was driven more by dynamics of creative restructuring of State-owned and State-participated firms rather than sheer Schumpeterian patterns of creative destruction. Indeed, the drivers of catching-up in China have been more the State-owned enterprises, and various forms of State-private ventures than the purely private ones.

After the Southern Tour of Deng Xiaoping in 1992, the process of restructuring of SOEs started,

\footnotetext{
${ }^{1}$ In the following, the reference to a U-shaped pattern refers to the behaviour across quantiles and has to be distinguished from the existence of any underling $U$ functional form in the sense of Haans et al. (2016).
} 
with an intensification phase from 1993 to 2003. The restructuring process was meant to render SOEs ever-more competitive in those sectors defined as strategic ones, such as telecommunication, computers, various "heavy industries", transportation and energy. Importantly, SOEs dramatically reduced their role as comprehensive welfare providers. As a result of this series of reforms, the occupational share of SOEs largely shrank, shedding 28 millions of workers and reducing the number of SOEs from 120 to 32 thousand in 2004 (see Xia et al. 2014).

Dong (2005) investigates the dynamics of wage inequality and compares the drivers more linked to observable worker individual characteristics, such as education, with those linked to firm characteristics: the findings suggest that it is where you work and not who you are that more contributed to raising wage inequality. A complementary analysis regarding the role of SOEs in the evolution of wage dispersion is undertaken in Appleton et al. (2014) using CHIP urban household survey data. The authors document that since the beginning of the market transition of SOEs in 1986, although the centralised wage setting process was gradually dismantled, SOEs tended to more equally distribute bonuses to workers, in particular providing higher bonuses for low-wage workers, and relatively lower ones for high-wage workers. The opposite instead occurred inside private firms, wherein a more market-prone wage setting scheme has been adopted, rewarding more, the more proficient workers.

Another stream of literature has been looking at the relationship between wage inequality and trade openness. In particular, Han et al. (2012) document a pattern of increasing wage inequality, using Chinese Urban Household Survey data from 1988 to 2008, by means of a quantile regression strategy controlling for the impacts produced by the Southern Tour (1992) and the WTO China adherence (2001) for low, medium and high wage percentiles. Some other studies focus on the reverse causation, from wages to productivity, and look at the effects of minimum wage regulations, as China since 2004 has strongly reinforced the sanctions for not compliant firms. Hau et al. (2016) report on the so called cleansing effects of minimum wage. The higher labour costs might have triggered processes of internal restructuring. Conversely, negligible impacts of minimum wage upon employment are recorded (Mayneris et al., 2018), in line with the general evidence for advanced economies (Schmitt, 2013).

Overall the findings on wage convergence/divergence are rather controversial, with households data showing an increasing divergence, while manufacturing data, as we shall discuss, show convergence. In fact, households inequality grew notwithstanding the increase in nominal and real wages. On the one hand, some authors point at the potential erosion of the immense unlimited supply of labour from agricultural areas, as signalled by the "dramatic" nominal wage growth for migrant workers in the urban areas from 2003 to 2009 (Fang and Yang, 2011). On the other hand, as we shall show, labour productivity over the same period increased by almost one order of magnitude more: hence, whether the so called Lewis turning point has been reached is still a major question mark.

In the following we enrich the current understanding of the dynamics of wage and productivity dispersions and jointly study the dynamic of the pass-through from the latter to the former. Basically, there are two major stylised facts which we are going to document in this work. First, elasticities are greater than zero - hence, strictly speaking, no "unlimited supply of labour" applies, and second, such elasticities are much smaller than one - indeed often around one-tenth - suggesting a pattern of income distribution biased toward increasing profits.

In order to provide a long run picture of the wage-productivity elasticity let us begin with aggregate manufacturing data. Figure 1, left panel, shows the wage-productivity elasticities, i.e. the 
ratio between the percentage change of real wage and the percentage change of labour productivity, for China's manufacturing sector since 1979 (both annual, blue line, and three years moving average, red line). One can observe three periods of decreasing elasticities (pass-through): the first one between mid-1980s to mid-1990s characterized by the decentralization of State power and an increasing decision-making autonomy of the SOEs; the second period between 2003-2008 (from the end of the restructuring of SOEs to the global financial crisis) characterized by the massive entry of domestic private-owned enterprises; the third one, from 2011 to the present, characterized by the slowing down of real wage growth.

Figure 1: Left panel: wage-productivity elasticities in the manufacturing sector (1978-2016). Right panel: comparison of elasticities, World Bank/CEIC vs. ASIE manufacturing dataset (1998-2007).
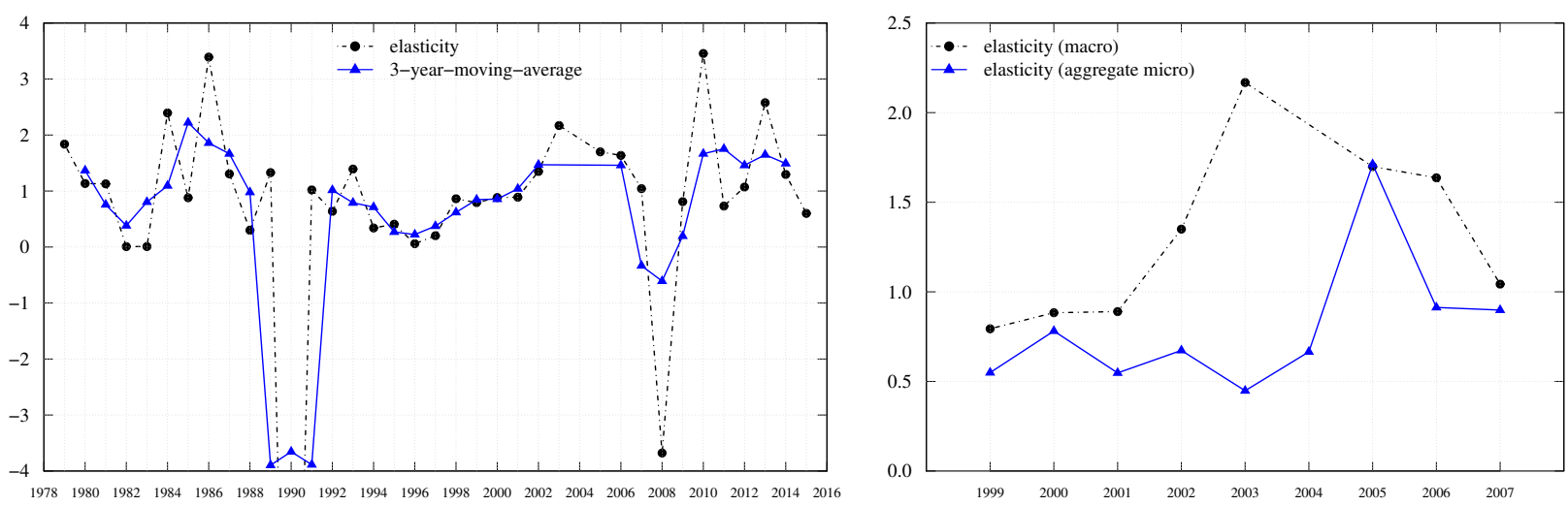

Sources: World Bank (real value added), NBSC and CEIC (employment growth). Note: the time series is not continuous in 2004 because it is a census year.

Along this time-span we shall focus on the period covered by our micro-level dataset (see below). Note that Figure 1, left panel, is recovered by the World Bank dataset to estimate real value added (retrieved in US dollars, adjusted into Chinese yuan using the exchange rate from OECD, and deflated using the Production Price Index from NBSC), by the NBSC (for the period 1978-1998) and CEIC (for the period 1999-2015) datasets ${ }^{2}$ to construct employment growth, and by the NBSC for the entire 19782016 period for average wage of staff and workers. Our micro-level dataset is restricted to firms above a certain turn-over threshold, covering the $90 \%$ of Chinese manufacturing value added. Among the latter, elasticities are systematically lower than in the former: cf. Figure 1, right panel. The discrepancy is due to an under-recorded productivity growth by the World Bank dataset.

\section{Data}

\subsection{Data description}

We draw upon firm level data from the Annual Survey of Industrial Enterprise (ASIE) collected by the National Bureau of Statistics of China (NBSC). The dataset includes all industrial firms with sales

\footnotetext{
${ }^{2}$ CEIC is a data company providing macro and micro economic data covering over 200 economies; the ultimate source of CEIC's China Premium Database is NBSC.
} 
above 5 million RMB covering the period $1998-2007^{3}$ and has already been employed in other empirical investigations, among others, Author A. ${ }^{4}$ The survey covers approximately 55 to 79 million workers, accounting for about $7.5 \%$ to $10.5 \%$ of the total Chinese employment. ${ }^{5}$ Each firm is assigned to a sector according to the 4-digit Chinese Industry Classification (CIC) system that closely matches the Standard Industrial Classification (SIC) employed by the U.S. Bureau of Census. ${ }^{6}$ Out of the comprehensive set of all firms, we focus on manufacturing firms only (CIC 13 - 42): Table 1 shows their summary statistics. The total number of employees in the manufacturing sector has increased from 50 in 1998 to 68 million in 2007, after a fall by 5.7 million from 1998 to 2001. The total output has increased from 5.93 to 35 trillion RMB in the same period and the number of firms from 148 to 310 thousand units approximately (see Table A.2 for the number of firms by ownership type). In the analysis that follows we apply a few cleaning procedures in order to eliminate visible recording errors, yielding what we call "China Micro Manufacturing" (CMM). ${ }^{7}$ And we keep firms existing for at least two consecutive years.

Table 1: Summary statistics (total) of the Chinese manufacturing firm-level dataset.

\begin{tabular}{cccccccccc}
\hline Year & $\begin{array}{c}\text { Number } \\
\text { of Firms }\end{array}$ & $\begin{array}{c}\text { Value } \\
\text { Added }\end{array}$ & Sales & Output & Emp & Wage & Welfare & $\begin{array}{c}\text { Cost of } \\
\text { labour }\end{array}$ \\
\hline 1998 & 148661 & 1.52 & 5.48 & 5.94 & 50.72 & 342.93 & 46.02 & 0.44 \\
1999 & 146075 & 1.68 & 5.96 & 6.37 & 47.36 & 351.00 & 46.18 & 0.45 \\
2000 & 147246 & 1.96 & 7.14 & 7.48 & 45.83 & 387.10 & 50.98 & 0.49 \\
2001 & 155659 & 2.22 & 7.99 & 8.40 & 44.95 & 416.39 & 54.01 & 0.50 \\
2002 & 165793 & 2.62 & 9.37 & 9.79 & 45.87 & 471.95 & 58.29 & 0.56 \\
2003 & 181001 & 3.40 & 12.38 & 12.72 & 48.71 & 549.46 & 67.81 & 0.65 \\
2004 & 258869 & 4.80 & 17.14 & 17.74 & 56.52 & 725.44 & 81.29 & 0.84 \\
2005 & 250952 & 5.71 & 21.34 & 21.74 & 59.21 & 885.13 & 101.51 & 1.02 \\
2006 & 278644 & 7.23 & 26.99 & 27.40 & 63.32 & 1090.65 & 123.65 & 1.25 \\
2007 & 312284 & 9.37 & 34.70 & 35.27 & 68.38 & 1415.58 & 139.62 & 1.60 \\
\hline
\end{tabular}

Note: all values are denoted in trillion RMB (wage and welfare are in billion RMB) and employment in millions of workers. All manufacturing firms are included. The output of year 2004 is not directly available from the original dataset, thus, we proxy it using "sales - year beginning inventory + year end inventory".

\subsection{Variables}

Labour productivity $\left(\pi_{i j t}\right)$ is the ratio of value added (at 1998 constant prices) over the number of employees, in logs. It is deflated by the 4-digit output deflator (source: Brandt et al. 2012). The choice of labour productivity rather than TFP is motivated by the following reasons. First, the proxy for capital is very noisy on Chinese data. Capital measures (in firm's balance sheet) are calculated as the value of fixed capital stock at original purchase prices (book values are the sum of nominal values for

\footnotetext{
${ }^{3}$ Available firm-level data for the following period (up to 2014) present missing elements for crucial variables. Additionally, after 2011 ASIE changed the scope of the survey, moving the threshold to 20 million RMB, therefore making the post-2011 data not comparable with ours.

${ }^{4}$ Industry is defined to include mining, manufacturing and public utilities, according to NBSC. Five million RMB is approximately \$US 600,000.

${ }^{5}$ The number of employees by firm ownership type is presented in Table A.3.

${ }^{6}$ In 2003, the classification system was revised. Some sectors were further disaggregated, while others were merged together. To make the industry code comparable over time, we adopted the harmonized classification proposed in Brandt et al. (2012).

${ }^{7}$ We dropped firms with missing, zero or negative output, value-added, sales, original value of fixed assets, with employment $<8$.
} 
different years). Second, as reported in Autor A, the within-country, within-sector micro correlations between labour productivities $(V A / L)$ and capital/output ratios $(K / V A)$, for whatever proxy for $K$, are robustly negative in China. In other words, labour and capital productivities are strongly positively correlated. In fact, labour productivities and capital/labour ratios - as a proxy of degrees of production mechanization/automation - are basically orthogonal. Overall, the evidence suggests that very little action comes from "moving along isoquants" in response to relative prices. Rather, "best practice" techniques involve a more efficient use of both labour and capital, and relatedly, catchingup fundamentally involves improvements on both dimensions. It is a world of complementarities rather than substitution, in which technology-gaps and learning efforts are both reflected by labour productivity differences, quite independently from relative prices, while TFP proxies might well yield a quite distorted picture of the development process. Indeed, given the ubiquitous complementarities between labour and capital, labour productivities alone turn out to be a robust proxy for the lower bound of "true" efficiency distributions, with the added advantage of avoiding any explicit or implicit hypothesis on interfactor substitutability and capital measurements.

Firm's total labour compensation is composed by wages, unemployment insurance and welfare benefits. Wage $\left(w_{i j t}\right)$ is the ratio of firm's total labour compensation (at 1998 constant prices) over the number of employees, in logs. It is deflated by the consumer price index (source: National Bureau of Statistics of China). Unfortunately we have a unique recorded wage per firm, therefore we can only account for the average wage. If anything, our elasticity might over-estimate the effective passthrough as the wage measure comprises both production/non-supervisory workers and supervisory ones (including managers). Dynamically, our wage measure might be further inflated by the potential differential growth of the number of supervisory/managerial vs production workers. Table 2 shows the summary statistics. Figure 2 shows the kernel density distributions of wages and labour productivities for three selected years. Already at a first glance some interesting patterns do emerge. While, not surprisingly, the support of the productivity distribution only partly overlaps with the wage distribution, over time the support of the former clearly moves to the right, but the support of the latter remains roughly constant. Together, a lower mode in the wage distribution hints at an increasing wage-productivity gap for the right tail of the distribution itself. Figure 3 shows the kernel density distributions of the growth rates of wage and labour productivity (beginning, mid-, end periods). The two distributions roughly overlap until 2001. Interestingly, both the lower and the upper tails of the wage growth distribution become much fatter since 2002, after the adherence to the WTO, indicating an increasing granularity of the wage growth rate.

We identify seven categories of firms according to their ownership and governance structures. They are State-owned enterprises (SOEs); collective-owned enterprises (COEs), Hong Kong, Macao and Taiwan-invested enterprises (HMTs); foreign-invested enterprises (FIEs), including foreign MNCs (FMNC) and joint ventures (JV) with a foreign share above 25\%; shareholding enterprises (SHEs), that is State-private Chinese joint ventures; private-owned enterprises (POEs); and other domestic enterprises (ODEs). ${ }^{8}$ Figure 4 shows the evolution of the means of wage and labour productivities by six major ownership types highlighting a generalised divergence in functional income distribution. Figure 5 and Table A.4 show the evolution of the wage-productivity elasticities by six major ownership types. Again, the year of WTO adherence is associated with a major negative shock in the latter

\footnotetext{
${ }^{8}$ As reported in Table A.1 in the Appendix, the original 23 registration categories have been aggregated in line with Jefferson et al. (2003).
} 
Table 2: Summary statistics (mean) of the dataset after cleaning.

\begin{tabular}{lccccccc}
\hline Year & $\begin{array}{c}\text { Number } \\
\text { of Firms }\end{array}$ & $\begin{array}{c}\text { Labour Pro- } \\
\text { ductivity }\end{array}$ & Wage & $\begin{array}{c}\text { (log-) Labour } \\
\text { Productivity }\end{array}$ & (log-) Wage & $\begin{array}{c}\text { Growth of } \\
\text { Labour } \\
\text { Productivity }\end{array}$ & $\begin{array}{c}\text { Growth of } \\
\text { Wage }\end{array}$ \\
\hline 1998 & 108286 & 44 & 9 & 3.101 & 1.873 & NA & NA \\
1999 & 125917 & 48 & 9 & 3.181 & 1.936 & 0.070 & 0.076 \\
2000 & 126054 & 54 & 10 & 3.314 & 2.038 & 0.061 & 0.076 \\
2001 & 138410 & 59 & 10 & 3.439 & 2.071 & 0.046 & -0.008 \\
2002 & 149189 & 68 & 11 & 3.569 & 2.152 & 0.083 & 0.067 \\
2003 & 162086 & 76 & 12 & 3.716 & 2.230 & 0.099 & 0.063 \\
2004 & 211534 & 88 & 13 & 3.817 & 2.345 & 0.047 & 0.089 \\
2005 & 238160 & 97 & 14 & 3.957 & 2.476 & 0.154 & 0.155 \\
2006 & 265912 & 114 & 17 & 4.118 & 2.616 & 0.171 & 0.158 \\
2007 & 248299 & 137 & 19 & 4.315 & 2.764 & 0.177 & 0.140 \\
\hline
\end{tabular}

Note: labour productivity and wages are at 1998 constant price, in 1000 RMB. Growth rates are calculated as log differences of real values over two consecutive years. Source: our elaboration on CMM.

Figure 2: Distribution of (log) wages and labour productivities (at 1998 constant price), years 1998, $2003,2007$.
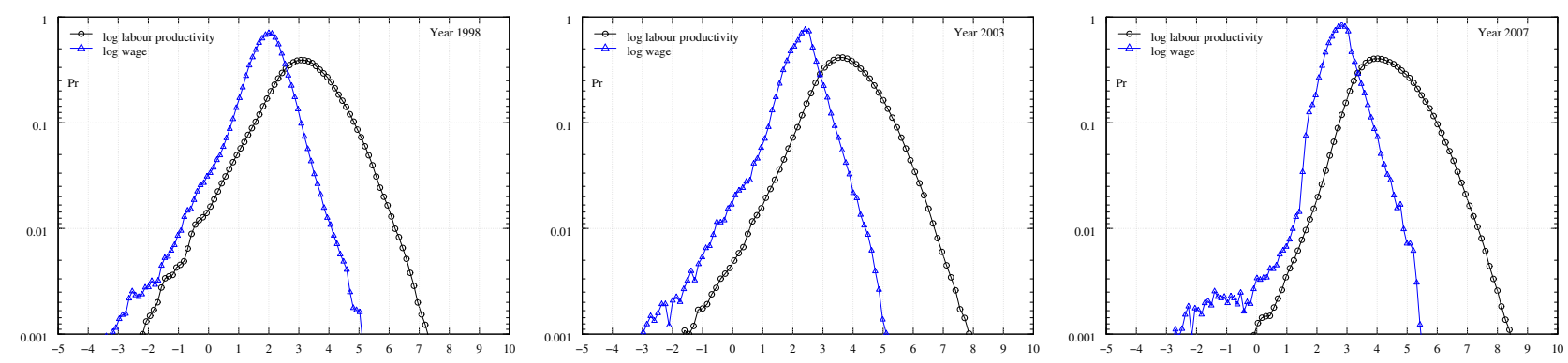

Pooling all firms in manufacturing. Source: our elaboration on CMM.

elasticities due to a dramatic decline in the rate of wage growth which in some of the ownership types becomes even negative. SOEs are among those two reporting the highest ratio in the entire time span.

\section{Convergence in wages and productivities dispersions across firms}

Moving a step deeper into the analysis of the degrees of heterogeneity, let us present alternative measures of dispersion for productivity and wages within narrowly defined sectors and/or ownership types. In the following we shall discuss interdecile ratios and shift-and-share variance decomposition of both variables.

\section{1. $90-10$ ratio}

The $90-10$ wage (productivity) ratio is defined as the ratio of the 90 th percentile to the 10 th percentile of the wage (productivity) distribution, also known as the interdecile range. Figure 6 shows the converging trend of both between-firm wage and productivity dispersions. The average wage in the highest paying firms, i.e. those at the $90 t h$ percentile of the wage distribution, were 2.7 times those at the bottom decile in 1998, and the ratio decreased to 1.7 in 2007. The productivity of firms at the $90 t h$ percentile of the productivity distribution were 2.7 times higher than those at the bottom decile, 
Figure 3: Distribution of growth rates of wage and of labour productivities, year 1999, 2003, 2007.
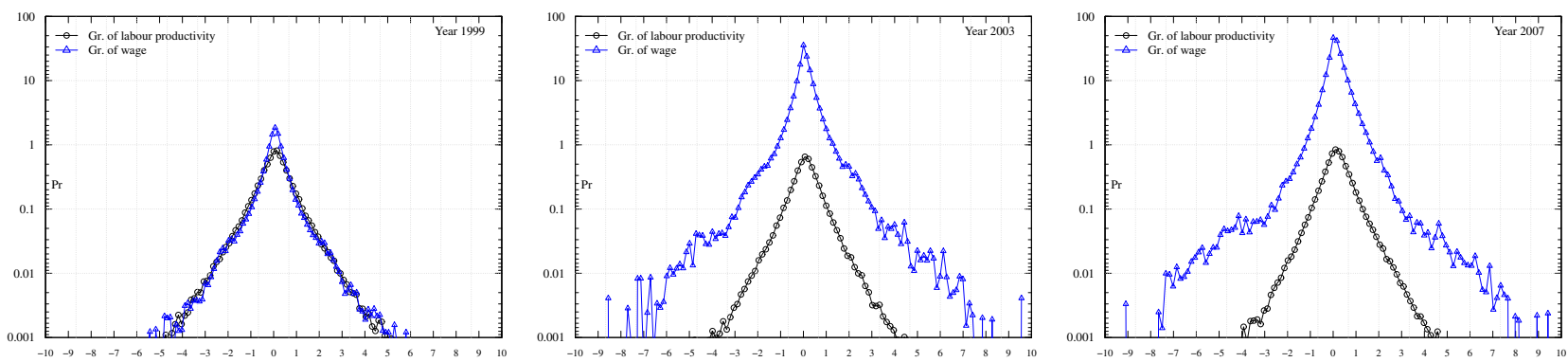

Pooling all firms in manufacturing. Source: our elaboration on CMM. All distributions are on the same scale.

Figure 4: Wages and labour productivities levels (means) by six major ownership types.
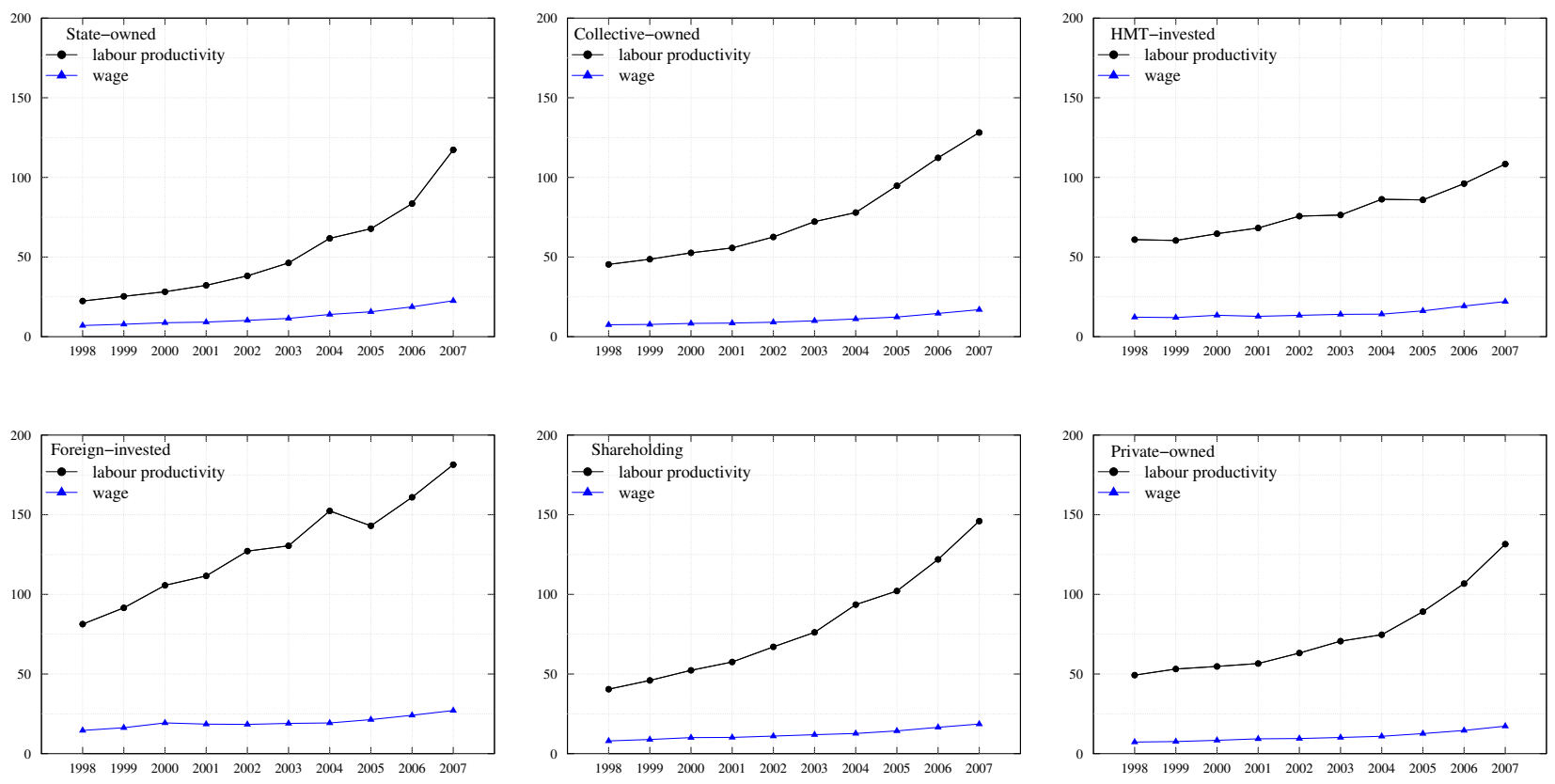

Source: our elaboration on CMM. 
Figure 5: Elasticities (growth of real wage per employee over growth of labour productivity) by six major ownership types.
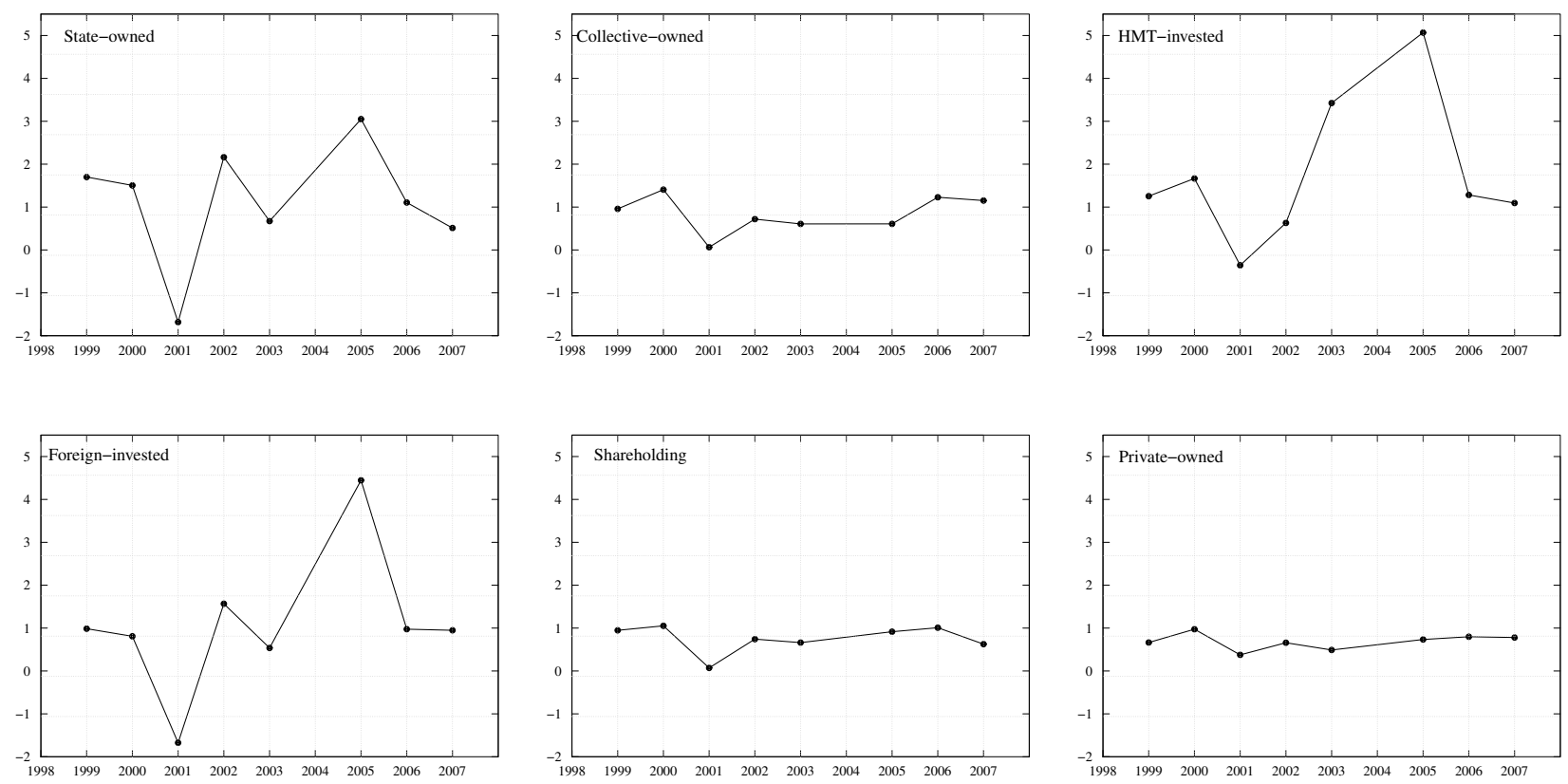

Source: Table A.4.

and 1.8 times in 2007. This sharp decline occurred for all ownership structures as shown in Figure A.2 and Table 3. Interestingly, SOEs present the highest initial ratios for wage and productivity dispersion in 1998, but they display also the steepest fall compared to other ownership types.

Figure 6: Wage/productivity 90-10 ratio by year, all manufacturing firms.

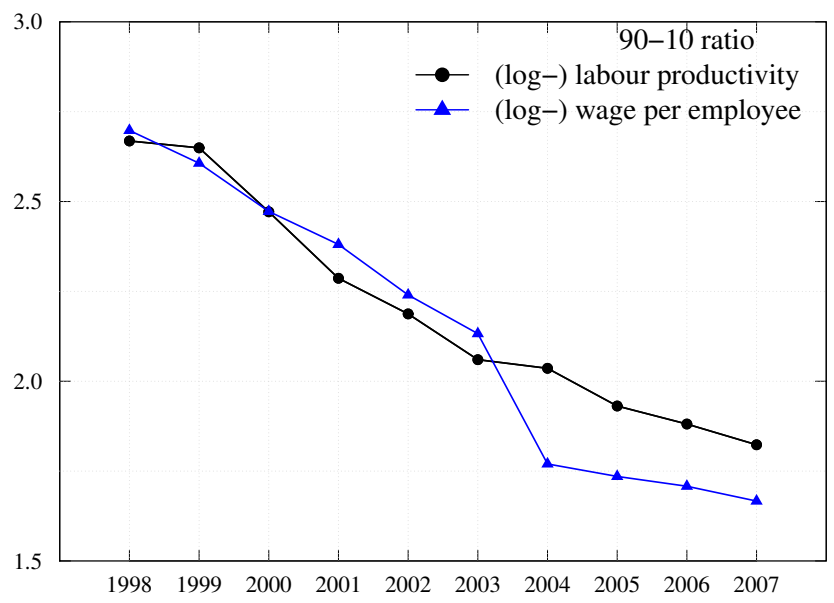

Note: equal weights. Source: our elaboration on CMM. 
Table 3: Wage/productivity 90-10 ratios, 90-50 ratios and 50-10 ratios by six major ownership types.

\begin{tabular}{|c|c|c|c|c|c|c|c|c|c|c|c|c|}
\hline \multirow[b]{3}{*}{ Ownership } & \multicolumn{4}{|c|}{ 90-10 ratio } & \multicolumn{4}{|c|}{ 90-50 ratio } & \multicolumn{4}{|c|}{$50-10$ ratio } \\
\hline & \multicolumn{2}{|c|}{ Productivity } & \multicolumn{2}{|c|}{ Wage } & \multicolumn{2}{|c|}{ Productivity } & \multicolumn{2}{|c|}{ Wage } & \multicolumn{2}{|c|}{ Productivity } & \multicolumn{2}{|c|}{ Wage } \\
\hline & 1998 & 2007 & 1998 & 2007 & 1998 & 2007 & 1998 & 2007 & 1998 & 2007 & 1998 & 2007 \\
\hline State-owned & 4.5 & 2.1 & 3.9 & 2.0 & 1.6 & 1.4 & 1.5 & 1.3 & 2.9 & 1.6 & 2.7 & 1.5 \\
\hline Collective-owned & 2.1 & 1.9 & 2.3 & 1.7 & 1.4 & 1.3 & 1.3 & 1.2 & 1.5 & 1.4 & 1.8 & 1.3 \\
\hline HMT-invested & 2.2 & 1.9 & 2.0 & 1.6 & 1.4 & 1.4 & 1.3 & 1.2 & 1.6 & 1.4 & 1.5 & 1.3 \\
\hline Foreign-invested & 2.2 & 1.9 & 2.2 & 1.7 & 1.4 & 1.4 & 1.4 & 1.3 & 1.6 & 1.4 & 1.6 & 1.3 \\
\hline Shareholding & 2.3 & 1.8 & 2.3 & 1.7 & 1.4 & 1.3 & 1.3 & 1.3 & 1.7 & 1.4 & 1.7 & 1.3 \\
\hline Private-owned & 2.1 & 1.8 & 2.3 & 1.6 & 1.4 & 1.3 & 1.3 & 1.2 & 1.5 & 1.3 & 1.8 & 1.3 \\
\hline
\end{tabular}

Figure 7: Wage (left)/productivity (right) at the top (90-50 ratio) versus bottom (50-10 ratio) of the distribution by year, all manufacturing firms.
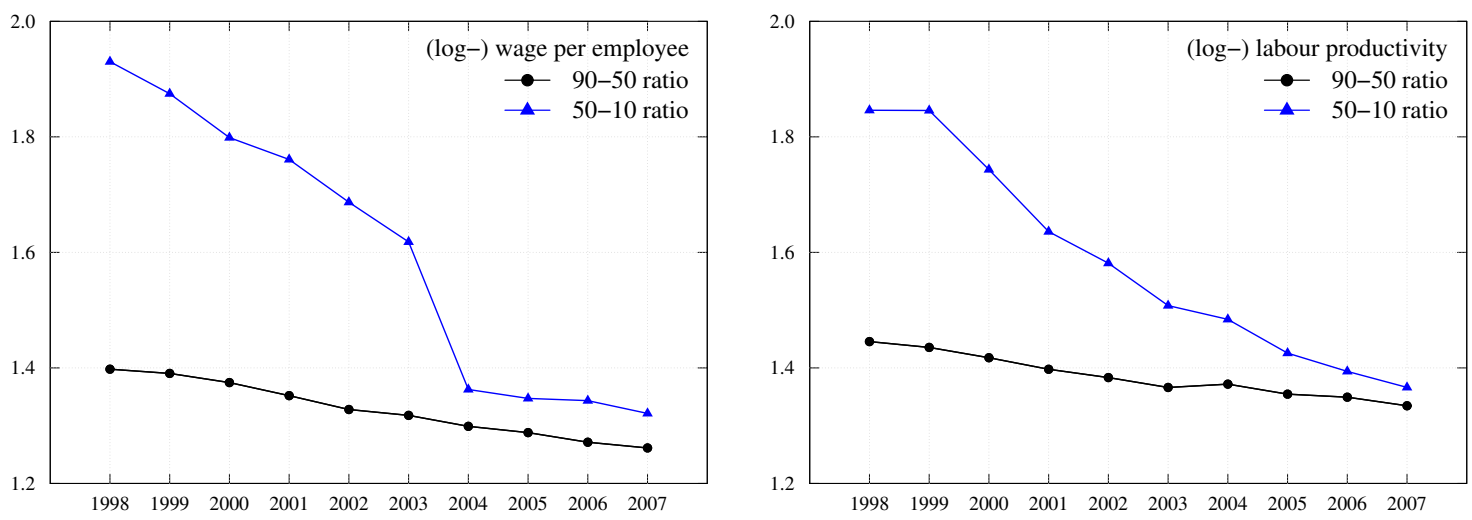

Note: equal weights. Source: our elaboration on CMM.

\section{2. $90-50$ and $50-10$ ratios}

In order to understand the source of the convergence, we split the $90-10$ ratio in two components. The $90-50$ wage (productivity) ratio is defined as the ratio of the $90 t h$ percentile to the $50 t h$ percentile (the median) of the wage (productivity) distribution. It captures the dispersion in the upper tail of the distribution. Symmetrically, the $50-10$ wage (productivity) ratio is the ratio of the $50 t h$ percentile to the 10th percentile of the wage (productivity) distribution, capturing the dispersion in the bottom tail of the distribution.

The evidence suggests that convergence is mainly driven by the push at the bottom of the wage distribution while only a very mild convergence has happened at the top (Figure 7 [left]). Interestingly there is a significant drop of the degree of divergence in the bottom part between 2003 and 2004, probably due also to the enforcement of the minimum wage legislation in 2004 . Figure 7 [right] shows the evolution of the top and the bottom of the productivity distributions, suggesting, again, that convergence has been more at the bottom, starting around 1999, when the process of SOEs restructuring was almost completed.

Disaggregating by ownership types, Figure A.3 shows the evolution of the top and bottom of the wage distribution. The discrete drop between 2003 and 2004 is more pronounced for all domestic ownership types, while wage adjustments have been smoother in foreign-invested firms. Figure A.4 reports the same analysis for productivity. Interestingly, the strongest converging trend at the top of productivity distribution concerns the domestic privately enterprises (POEs) and shareholding ones 
(SHEs). Note that convergence at the top might mean two opposite things, namely, that the top slows down with respect to the median, or, conversely, that the median catches-up with the top. Conversely, the strongest converging trend at the bottom concerns state-owned enterprises (SOEs) and shareholding ones (SHEs).

\subsection{Decomposition of wage/productivity variance}

Having detected some convergence processes in the distribution of both wages and productivity driven by the bottom part of the distribution, let us investigate by means of a shift and share decomposition the relative contribution of the within and between sectoral components. The (labour-weighted) variance of wage $\left(\operatorname{Var} w_{i j t}\right) /$ productivity $\left(\operatorname{Var} \pi_{i j t}\right)$ is decomposed into a within-sector component and a between-sector one, according to Berlingieri et al. (2017):

$$
\underbrace{\sum_{i} \frac{L_{i j t}}{L_{t}}\left(w_{i j t}-\bar{w}_{t}\right)^{2}}_{\operatorname{Var} w_{i j t}} \equiv \underbrace{\sum_{j} \frac{L_{j t}}{L_{t}} \sum_{i \in j} \frac{L_{i j t}}{L_{j t}}\left(w_{i j t}-\bar{w}_{j t}\right)^{2}}_{\text {within }}+\underbrace{\sum_{j} \frac{L_{j t}}{L_{t}}\left(\bar{w}_{j t}-\bar{w}_{t}\right)^{2}}_{\text {between }}
$$

where $L_{i j t}$ is the number of employees of firm $i$ in sector $j$ at time $t$; $L_{j t}$ is the total number of employees of sector $j$ at time $t ; L_{t}$ is the total number of employees at time $t ; \bar{w}_{t}=\sum_{i} \sum_{j} \frac{L_{i j t}}{L_{t}} w_{i j t}$ is the grand (labour) weighted mean of wages; $\bar{w}_{j t}=\sum_{i \in j} \frac{L_{i j t}}{L_{j t}} w_{i j t}$ is the sectoral (labour) weighted mean of wages. The decomposition is done by pooling all firms in manufacturing for each 2-digit sector. ${ }^{9}$

As shown in Table 4 and in Table 5, the within-sector (between-firms) component accounts for around $80 \%$ of the wage (productivity) dispersion in each 2-digit sector, every year. The results corroborate an increasing empirical literature documenting that the between firms wage/productivity variation is the major driver of the observed heterogeneity. Figure 8 shows the evolution of the shares of the within-sectoral wage/labour productivity dispersions: while the within sectoral component of productivity dispersion presents a clear decreasing trend, the same does not occur for the sectoral component of wage dispersion, which oscillates between $87 \%$ and $84 \%$ in the period under study. It is an interesting and suggestive piece of evidence. The fall of the within-sector component in productivity dynamics hints at a generalized catching-up process cutting across all manufacturing, steadily reducing dualism, as the classics of development theory would have argued, between a modern/dynamic part of the industry and an informal/backward one. Conversely, the persistency of the within component in wages strongly suggests a persistent heterogeneity in labour market conditions, and in bargaining and power relations between firms and workers.

The conjecture is supported by the evidence on the evolution of the share of within-sector wage and labour productivity dispersions by the six major ownership types (see Figure A.5). This allows to disentangle the different behaviour of State owned vs. private firms. So the within share of the total wage variance of SOEs is much lower than other ownership types and decreasing from 78\% in 1998 to $60 \%$ in 2007. Conversely, that of domestic private firms (POEs) increases from $80 \%$ to $95 \%$ in 2007. A similar pattern does also characterize the within share of productivity variance, with a decreasing within share of SOEs, from $70 \%$ to $50 \%$ in 2007 and an increasing within share of POEs, from $70 \%$ to

\footnotetext{
${ }^{9}$ Note: deviation from the labour-weighted 4-digit wage mean.
} 
Table 4: Share of within-sector wage variance.

\begin{tabular}{|c|c|c|c|c|c|c|c|c|c|c|c|}
\hline CIC & SECTOR & 1998 & 1999 & 2000 & 2001 & 2002 & 2003 & 2004 & 2005 & 2006 & 2007 \\
\hline & Whole manufacturing & 87.0 & 85.3 & 85.5 & 85.6 & 84.2 & 84.9 & 84.1 & 85.1 & 85.9 & 87.1 \\
\hline 13 & Processing of food from agricultural products & 92.2 & 94.4 & 95.1 & 87.8 & 85.4 & 94.9 & 97.5 & 97.3 & 98.4 & 98.3 \\
\hline 14 & Foodstuff & 93.2 & 96.2 & 94.6 & 94.3 & 90.3 & 94.8 & 94.8 & 94.3 & 94.5 & 95.8 \\
\hline 15 & Manuf. of beverages & 92.9 & 91.7 & 91.9 & 93.7 & 92.3 & 93.2 & 86.3 & 90.0 & 90.3 & 89.9 \\
\hline 16 & Manuf. of tobacco & 89.2 & 89.4 & 88.3 & 90.6 & 87.0 & 82.3 & 61.7 & 80.1 & 85.1 & 66.8 \\
\hline 17 & Manuf. of textile & 97.6 & 96.4 & 95.5 & 96.6 & 96.0 & 96.5 & 96.3 & 96.7 & 95.1 & 96.3 \\
\hline 18 & Manuf. of textile wearing apparel, footwear, cand caps & 98.8 & 99.3 & 99.7 & 99.7 & 99.0 & 99.5 & 99.7 & 99.9 & 99.8 & 99.5 \\
\hline 19 & Manuf. of leather, fur, feather and related products & 99.0 & 98.1 & 98.5 & 98.5 & 99.0 & 99.1 & 99.6 & 99.5 & 99.6 & 98.7 \\
\hline 20 & Processing of timber, manufacture of wood, bamboo, & 97.3 & 96.9 & 95.9 & 95.3 & 97.5 & 94.7 & 97.3 & 96.1 & 97.4 & 97.0 \\
\hline 21 & Manuf. of furniture & 98.8 & 98.2 & 96.8 & 95.2 & 96.5 & 97.8 & 98.7 & 97.9 & 97.0 & 98.2 \\
\hline 22 & Manuf. of paper and paper products & 99.5 & 99.4 & 99.2 & 99.2 & 99.6 & 99.3 & 99.3 & 99.1 & 99.3 & 98.0 \\
\hline 23 & Printing, reproduction of recording media & 98.9 & 99.2 & 98.1 & 97.7 & 98.5 & 99.1 & 99.5 & 99.7 & 98.8 & 99.5 \\
\hline 24 & Manuf. of articles for culture, education and sport activity & 94.5 & 93.8 & 95.3 & 95.8 & 95.3 & 96.9 & 96.4 & 97.8 & 98.7 & 98.7 \\
\hline 25 & Processing of petroleum, coking, processing of nuclear fuel & 89.1 & 77.9 & 80.8 & 93.5 & 79.3 & 73.0 & 76.3 & 71.0 & 72.0 & 82.3 \\
\hline 26 & Manuf. of raw chemical materials and chemical products & 93.0 & 75.8 & 93.4 & 92.6 & 93.8 & 90.4 & 91.5 & 92.9 & 93.2 & 93.8 \\
\hline 27 & Manuf. of medicines & 97.9 & 98.1 & 97.5 & 98.7 & 98.3 & 96.7 & 97.2 & 97.1 & 98.0 & 98.4 \\
\hline 28 & Manuf. of chemical fibers & 93.0 & 85.2 & 88.2 & 91.3 & 93.6 & 94.6 & 92.7 & 75.7 & 83.3 & 85.2 \\
\hline 29 & Manuf. of rubber & 98.3 & 94.1 & 88.1 & 95.6 & 94.4 & 93.9 & 94.2 & 93.0 & 95.5 & 96.1 \\
\hline 30 & Manuf. of plastics & 97.4 & 97.2 & 96.1 & 96.0 & 98.4 & 97.2 & 96.9 & 97.1 & 95.9 & 96.5 \\
\hline 31 & Manuf. of non-metallic mineral products & 96.4 & 95.2 & 94.1 & 94.5 & 94.6 & 95.6 & 95.6 & 92.8 & 93.9 & 94.4 \\
\hline 32 & Smelting and pressing of ferrous metals & 84.9 & 84.5 & 82.7 & 82.9 & 77.1 & 82.0 & 85.7 & 85.7 & 88.0 & 88.8 \\
\hline 33 & Smelting and pressing of non-ferrous metals & 87.2 & 91.1 & 84.4 & 88.9 & 83.9 & 86.6 & 90.0 & 88.2 & 88.9 & 90.3 \\
\hline 34 & Manuf. of metal products & 93.4 & 94.3 & 93.9 & 98.0 & 93.7 & 95.8 & 94.8 & 95.8 & 97.6 & 96.7 \\
\hline 35 & Manuf. of general purpose machinery & 92.2 & 93.8 & 92.2 & 96.1 & 95.3 & 94.2 & 94.5 & 95.4 & 94.3 & 94.7 \\
\hline 36 & Manuf. of special purpose machinery & 92.1 & 90.7 & 89.2 & 89.5 & 89.5 & 88.8 & 92.0 & 93.0 & 92.3 & 90.3 \\
\hline 37 & Manuf. of transport equipment & 89.9 & 91.7 & 86.4 & 86.6 & 84.7 & 84.5 & 85.7 & 87.7 & 82.7 & 88.8 \\
\hline 39 & Manuf. of electrical machinery and equipment & 95.0 & 90.0 & 97.4 & 96.2 & 95.9 & 95.0 & 93.6 & 95.8 & 95.9 & 96.2 \\
\hline 40 & $\begin{array}{l}\text { Manuf. of communication equipment, computers and other electronic } \\
\text { equipment }\end{array}$ & 90.7 & 89.3 & 89.2 & 91.7 & 88.4 & 88.7 & 77.9 & 84.2 & 89.5 & 88.5 \\
\hline 41 & $\begin{array}{l}\text { Manuf. of measuring instruments and machinery for cultural activity and } \\
\text { office work }\end{array}$ & 89.7 & 93.3 & 85.9 & 95.4 & 92.4 & 93.2 & 91.6 & 90.6 & 86.9 & 88.5 \\
\hline 42 & Manuf. of artwork and other manufacturing & 83.4 & 90.4 & 89.9 & 89.7 & 96.2 & 93.3 & 95.3 & 95.5 & 94.0 & 95.1 \\
\hline
\end{tabular}

Note: variance is labour weighted.

$85 \%$. That is, under our foregoing conjecture, SOEs converged more consistently as a whole.

\section{A quantile regression analysis of the wage-productivity nexus}

In order to further analyse the wage-productivity nexus, let us first consider standard pooled OLS estimates. Recall from Figure 2 that looking at levels, both wage and productivity distributions display skewness and fat tails. At the same time growth rates are tent-shaped. All this evidence on deep heterogeneity and lack of Gaussian features militates in favour of the use of quantile regression analysis, robust as it is to outliers and heavy tailed distributions (Koenker and Hallock, 2001). With respect to our own dataset, Figure 9 presents the scatter plot of the wage-productivity nexus, both in level (top panel) and in growth rates (bottom panel), for three representative 4-digit sectors. The dashed lines present the least-square estimates, while the grey lines present the quantiles in the range of $0.05-0.95$. If the least-squares estimate had correctly captured the relationship, all the grey lines and the dashed line would have been parallel. On the contrary already at a first glance does emerge an increasing dispersion for higher and lower quantiles vis-à-vis the median one. The poor performance of the OLS estimates to capture the underlying relationships prompts quantile regression estimates (Koenker, 2005). In the following, we shall present pooled and dynamic quantile estimates in levels and growth rates. Finally, we shall look at the relationship between means and variances in productivity and wages.

\subsection{Quantile regression}

The quantile regression model (Koenker and Bassett Jr, 1978) reads as: 
Table 5: Share of within-sector labour productivity variance.

\begin{tabular}{|c|c|c|c|c|c|c|c|c|c|c|c|}
\hline CIC & SECTOR & 1998 & 1999 & 2000 & 2001 & 2002 & 2003 & 2004 & 2005 & 2006 & 2007 \\
\hline & Whole manufacturing & 82.7 & 83.5 & 83.5 & 82.4 & 81.1 & 78.7 & 78.0 & 78.7 & 78.0 & 77.7 \\
\hline 13 & Processing of food from agricultural products & 89.6 & 93.9 & 95.1 & 93.3 & 91.9 & 92.8 & 92.4 & 92.0 & 92.1 & 90.3 \\
\hline 14 & Foodstuff & 83.9 & 89.4 & 86.6 & 86.8 & 86.8 & 89.0 & 92.2 & 90.4 & 89.5 & 90.0 \\
\hline 15 & Manuf. of beverages & 92.6 & 94.4 & 93.9 & 93.4 & 92.2 & 90.8 & 91.8 & 95.0 & 95.6 & 95.3 \\
\hline 16 & Manuf. of tobacco & 85.3 & 84.1 & 84.5 & 86.5 & 88.6 & 73.6 & 50.3 & 61.6 & 52.6 & 51.7 \\
\hline 17 & Manuf. of textile & 94.0 & 94.5 & 94.5 & 93.1 & 92.6 & 94.4 & 96.5 & 95.9 & 96.1 & 96.8 \\
\hline 18 & Manuf. of textile wearing apparel, footwear, cand caps & 99.2 & 98.2 & 97.2 & 98.7 & 99.3 & 98.6 & 99.3 & 99.3 & 98.9 & 99.5 \\
\hline 19 & Manuf. of leather, fur, feather and related products & 96.1 & 96.0 & 93.2 & 91.9 & 91.5 & 86.1 & 88.0 & 85.1 & 86.4 & 83.7 \\
\hline 20 & Processing of timber, manufacture of wood, bamboo, & 98.5 & 96.6 & 97.4 & 97.4 & 95.8 & 90.8 & 94.0 & 93.4 & 94.6 & 93.6 \\
\hline 21 & Manuf. of furniture & 97.0 & 97.7 & 97.8 & 97.2 & 97.1 & 98.9 & 96.6 & 97.4 & 98.2 & 98.7 \\
\hline 22 & Manuf. of paper and paper products & 99.3 & 99.7 & 99.3 & 99.8 & 99.3 & 99.3 & 98.8 & 97.7 & 97.6 & 96.8 \\
\hline 23 & Printing, reproduction of recording media & 94.1 & 96.2 & 94.6 & 91.5 & 94.0 & 93.2 & 95.6 & 96.2 & 96.0 & 95.7 \\
\hline 24 & Manuf. of articles for culture, education and sport activity & 92.4 & 90.7 & 89.5 & 86.5 & 91.3 & 90.1 & 92.7 & 93.5 & 93.1 & 93.4 \\
\hline 25 & Processing of petroleum, coking, processing of nuclear fuel & 72.0 & 68.8 & 81.9 & 71.7 & 69.3 & 69.2 & 67.4 & 76.4 & 75.6 & 82.5 \\
\hline 26 & Manuf. of raw chemical materials and chemical products & 90.6 & 81.6 & 89.9 & 89.4 & 90.2 & 86.5 & 85.8 & 90.2 & 91.2 & 91.4 \\
\hline 27 & Manuf. of medicines & 97.1 & 97.3 & 97.0 & 96.6 & 97.1 & 95.5 & 97.0 & 96.2 & 96.9 & 96.6 \\
\hline 28 & Manuf. of chemical fibers & 91.8 & 88.4 & 85.4 & 92.1 & 96.1 & 95.4 & 98.9 & 87.3 & 82.7 & 81.4 \\
\hline 29 & Manuf. of rubber & 79.3 & 83.9 & 80.9 & 82.2 & 82.9 & 79.5 & 79.9 & 76.6 & 77.8 & 76.6 \\
\hline 30 & Manuf. of plastics & 97.4 & 95.2 & 95.2 & 95.0 & 93.4 & 94.3 & 92.0 & 92.2 & 92.0 & 90.6 \\
\hline 31 & Manuf. of non-metallic mineral products & 93.2 & 92.7 & 90.6 & 88.7 & 86.7 & 87.2 & 87.0 & 86.1 & 88.0 & 87.4 \\
\hline 32 & Smelting and pressing of ferrous metals & 94.8 & 94.0 & 93.1 & 91.9 & 89.2 & 89.9 & 91.5 & 90.1 & 90.8 & 94.8 \\
\hline 33 & Smelting and pressing of non-ferrous metals & 96.5 & 94.1 & 96.6 & 92.8 & 92.2 & 92.5 & 92.7 & 90.0 & 89.6 & 90.0 \\
\hline 34 & Manuf. of metal products & 93.0 & 94.3 & 94.3 & 94.1 & 94.5 & 94.0 & 89.9 & 92.6 & 93.0 & 93.4 \\
\hline 35 & Manuf. of general purpose machinery & 93.8 & 96.5 & 95.1 & 95.5 & 95.7 & 93.4 & 94.5 & 93.7 & 92.2 & 93.0 \\
\hline 36 & Manuf. of special purpose machinery & 85.2 & 86.6 & 80.1 & 85.6 & 87.5 & 86.6 & 90.7 & 94.5 & 93.7 & 92.5 \\
\hline 37 & Manuf. of transport equipment & 89.0 & 89.9 & 92.7 & 87.4 & 79.7 & 75.7 & 83.6 & 81.1 & 79.0 & 80.1 \\
\hline 39 & Manuf. of electrical machinery and equipment & 85.0 & 85.4 & 90.5 & 86.7 & 89.0 & 88.0 & 86.7 & 87.8 & 86.5 & 84.9 \\
\hline 40 & $\begin{array}{l}\text { Manuf. of communication equipment, computers and other electronic } \\
\text { equipment }\end{array}$ & 84.8 & 87.3 & 84.9 & 86.0 & 84.4 & 86.4 & 86.9 & 88.7 & 88.4 & 89.8 \\
\hline 41 & $\begin{array}{l}\text { Manuf. of measuring instruments and machinery for cultural activity and } \\
\text { office work }\end{array}$ & 88.4 & 86.4 & 88.6 & 89.5 & 91.4 & 87.0 & 84.7 & 83.5 & 78.6 & 76.9 \\
\hline 42 & Manuf. of artwork and other manufacturing & 83.1 & 94.1 & 94.9 & 94.1 & 95.8 & 96.7 & 96.3 & 95.9 & 96.2 & 97.2 \\
\hline
\end{tabular}

Note: variance is labour weighted.

Figure 8: Share of within-sector wage/labour productivity dispersion.

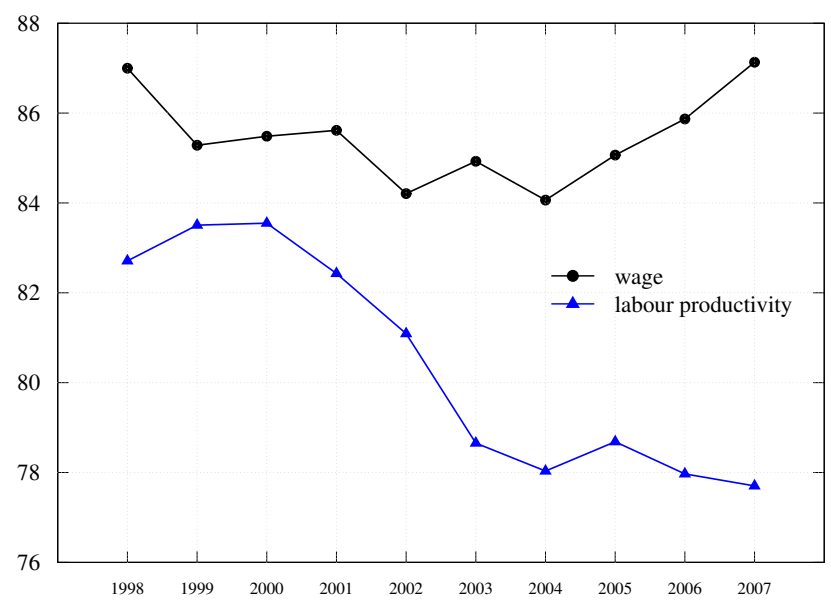

Note: pooling all firms in manufacturing sector, deviation from the 4-digit sectoral labour-weighted mean. Source: our elaboration on CMM. 
Figure 9: Scatterplot and quantile regression fit.
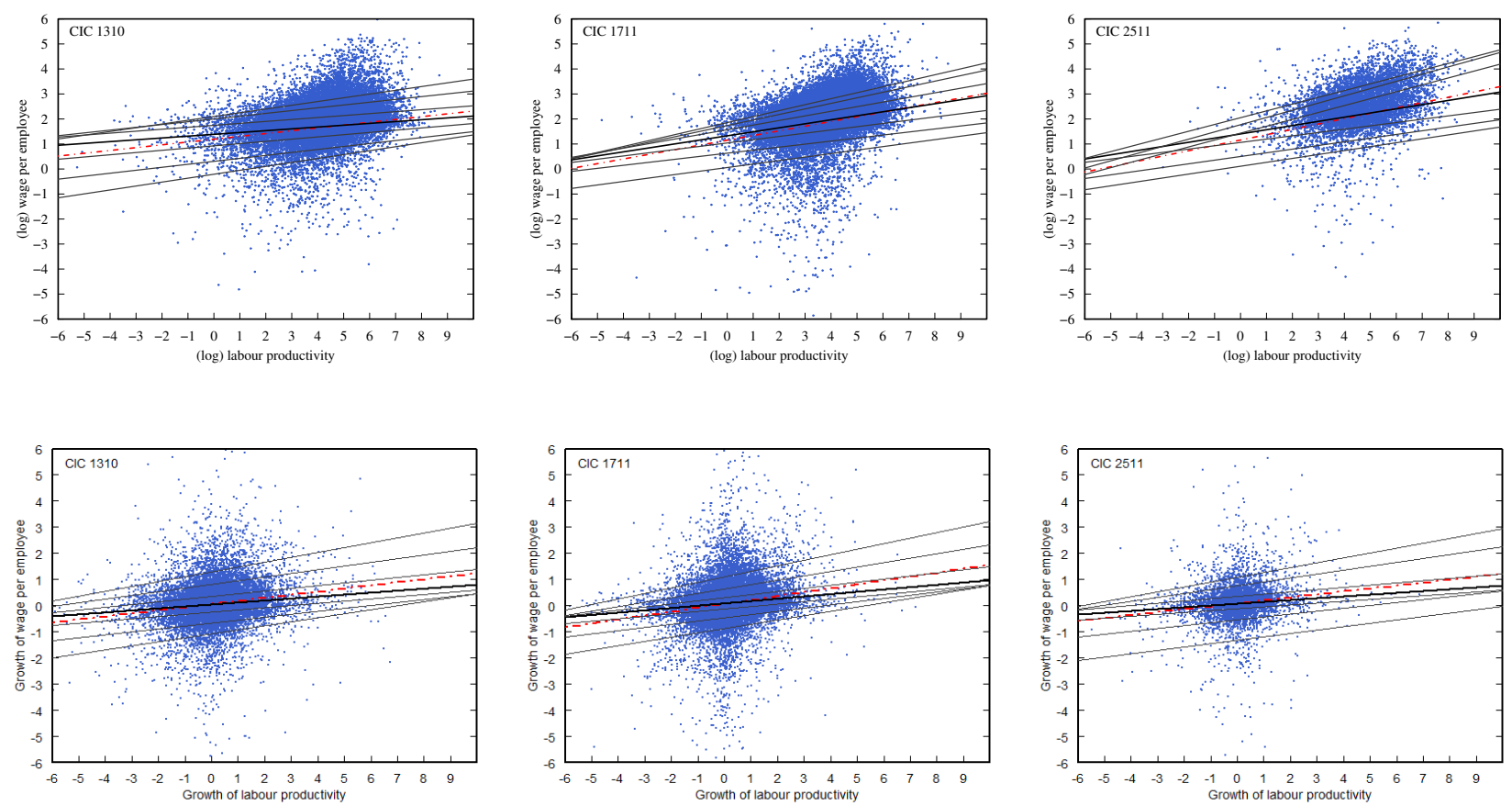

The plots in the first row show a scatter plot on wage level vs. productivity level of three representative 4-digit sectors (manufacturing of textile clothing, plastic, communication transmitting equipment). The plots in the second row show a scatter plot on wage growth vs. productivity growth. Superimposed on the plots are the $0.05,0.1,0.25,0.75,0.90,0.95$ quantile regression lines in grey, the median fit in solid black, and the least-squares estimate of the conditional mean function as the dashed line (Koenker, 2005). Source: our elaboration on CMM.

$$
y_{i t}=x_{i t}^{\prime} \beta_{\tau}+u_{\tau i t} \quad \text { with } \quad \mathrm{Q}_{\tau}\left(y_{i t} \mid x_{i t}\right)=x_{i t}^{\prime} \beta_{\tau}
$$

where $y_{i t}$ is the dependent variable, $x$ is a set of regressors, $\beta$ is the vector of parameters to be estimated, and $u$ is a vector of residuals. $\mathrm{Q}_{\tau}\left(y_{i t} \mid x_{i t}\right)$ stands for the $\tau^{t h}$ conditional quantile of $y_{i t}$ given $x_{i t}$. The $\tau^{\text {th }}$ conditional quantile solves the minimization problem:

$$
\beta_{\tau} \equiv \underset{b}{\operatorname{argmin}} E\left[\rho_{\tau}\left(y_{i t}-x_{i t}^{\prime} b\right)\right]
$$

where $\rho(u)=1(u>0) \cdot \tau|u|+1(u \leq 0) \cdot(1-\tau)|u|$ is called the "check function". If $\tau=0.5$, this turns out in terms of least absolute deviations. In this case, $\mathbf{Q}_{\tau}\left(y_{i t} \mid x_{i t}\right)$ is the conditional median since it minimizes absolute deviations. Otherwise, the check function weights positive and negative terms asymmetrically. The quantile regression estimator, $\hat{\beta}_{\tau}$ is the sample analogy of Equation 3 . This minimization procedure involves the solution of a linear programming problem. As one increases $\tau$ from 0 to 1 , one traces the entire conditional distribution of $y_{i t}$ on $x_{i t}$. 


\subsection{Wage - productivity levels}

In the first model we mean to detect the relationship between the level of productivity and the level of wages. ${ }^{10}$ The model, estimated at the highest levels of sectoral disaggregation (four-digit) at the $0.05,0.10,0.25,0.50,0.75,0.90,0.95$ quantiles of the conditional wage level distribution, reads as:

$$
w_{i t}=\alpha+\beta_{\tau} \pi_{i t}+y_{t}+\epsilon_{\tau i t}
$$

where $w_{i t}$, the dependent variable, is the $(\log )$ real wage per employee for firm $i$ at time $t, \pi_{i t}$ the (log) labour productivity level. We also control for common macroeconomic shocks by including year dummies $y_{t}$. The violin plot in Figure 10 presents the median, the interquartile ranges, and the kernel density distribution of the coefficient estimates for each quantile of the conditional wage distribution. The estimated coefficients present a monotonic increasing pattern, meaning that the wage-productivity nexus increases along the conditional wage distribution. ${ }^{11}$ Violin plots have been usually employed to present OLS estimates across narrowly defined sectors (Dosi et al., 2015). To the best of our knowledge this is one the few attempts using violin plots to synthetically present both the kernel density distribution at four-digit sector and the distribution across quantiles of the dependent variable.

At the lower quantiles of the conditional wage distribution the coefficients on labour productivity are the lowest and conversely they are remarkably higher at the upper tail of the conditional wage distribution, wherein $10 \%$ increase in labour productivity tends to raise the 90th and 95th quantiles of wage distribution by $2.64 \%$ and $2.76 \%$ respectively. ${ }^{12}$ We have performed the nonparametric KruskalWallis test (Kruskal and Wallis, 1952) to detect the median differences across the distributions at the seven quantiles of the conditional wage distribution in Figure 10. Upon rejection of the null hypothesis of this test, we conducted post hoc multiple pairwise comparisons for stochastic dominance or median difference using Dunn's test (Dinno, 2015) with a Bonferroni adjustment. The medians at the 90th and $95 t h$ are significantly higher than the medians at the $5 t h, 10 t h, 25 t h$ and $50 t h$ quantiles.

Based on the coefficient estimates from the quantile regression at the 4-digit sectoral level, one may predict the conditional quantile functions of wage that are at 10th and 90th percentiles of the sample productivity distribution. Figure 11 presents the estimated conditional wage distribution for the 4-digit sectors characterised by the highest number of observations. Indeed one does not find any strong regularity of wage dispersion at the $10 t h$ and $90 t h$ percentiles of productivity distribution, with some sectors displaying higher dispersion at the 90th rather than at the 10th percentile and others which do not. In this respect, the link between productivity levels and wage dispersion is not very robust to disaggregation by sector.

We further extended the analysis performing six separate estimations for each major ownership type. The result of the quantile regression estimates is shown in Figure 12, while the median values of the distribution of coefficients are reported in Table 6. State-owned enterprises present the highest association between productivity and wage level with a monotonic decreasing relationship along the

\footnotetext{
${ }^{10}$ Productivity is a very persistent, strongly autocorrelated variable. Therefore we deem appropriate to perform contemporaneous estimates of the model in levels. Later on, in order to capture the time dimension we estimate the model in terms of rates of growth.

${ }^{11}$ The observed monotonic increasing pattern is robust to higher levels of aggregation with estimates of Equation (4) pooling all manufacturing firms and including 2-digit sectoral dummies. Results are available upon request.

${ }^{12}$ The reported coefficients are statistically different from zero for the majority of the sectors in this and subsequent model estimates.
} 
Figure 10: Distributions of quantile regression coefficients across 424 four-digit sectors.

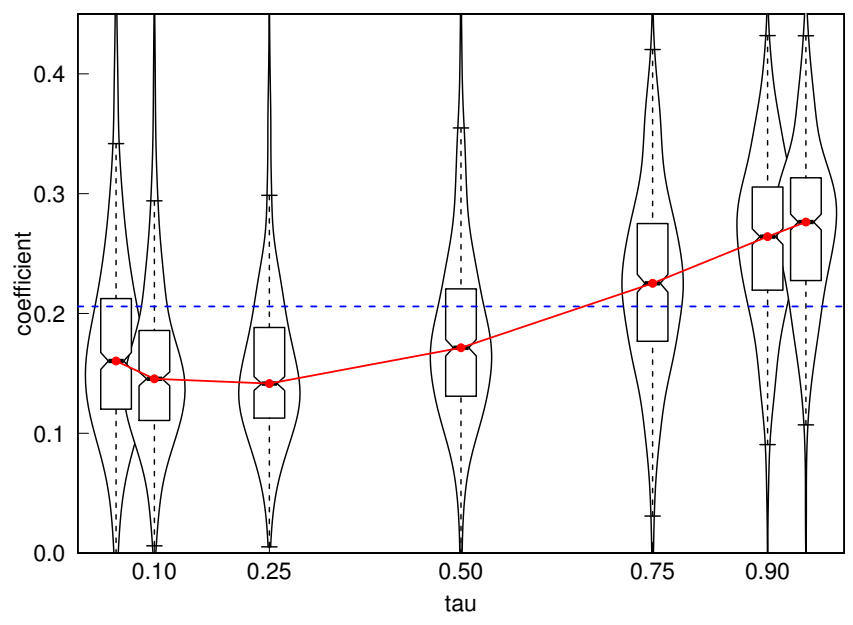

Note: quantile regression estimation of equation (4) for each 4-digit sector, the coefficient of log- labour productivity reported for the $0.05,0.10,0.25,0.50,0.75,0.90$ and 0.95 quantiles. Each violin reports a box plot and a kernel density to each side of the box plot. The median of Pseudo $R^{2}$ is 0.1426 for quantile regression. The dashed line is the median of the distribution of OLS estimates.

Table 6: Median of the distributions in Figure 12.

\begin{tabular}{lccccccc|ccc}
\hline & & \multicolumn{7}{c}{ Quantiles } & & \\
Ownership & 0.05 & 0.10 & 0.25 & 0.50 & 0.75 & 0.90 & 0.95 & OLS & $\beta_{1,0.95}-\beta_{1,0.05}$ & Pseudo $R^{2}$ (Median) \\
\hline State-owned & 0.348 & 0.319 & 0.293 & 0.292 & 0.262 & 0.227 & 0.211 & 0.277 & -0.137 & 0.1781 \\
Collective-owned & 0.173 & 0.134 & 0.116 & 0.119 & 0.154 & 0.203 & 0.229 & 0.162 & 0.056 & 0.1235 \\
HMT-invested & 0.137 & 0.138 & 0.161 & 0.194 & 0.221 & 0.251 & 0.267 & 0.201 & 0.130 & 0.1466 \\
Foreign-invested & 0.156 & 0.163 & 0.203 & 0.254 & 0.293 & 0.286 & 0.284 & 0.246 & 0.128 & 0.1414 \\
Shareholding & 0.162 & 0.144 & 0.147 & 0.169 & 0.212 & 0.249 & 0.262 & 0.198 & 0.100 & 0.1423 \\
Private-owned & 0.088 & 0.077 & 0.075 & 0.097 & 0.143 & 0.213 & 0.250 & 0.132 & 0.162 & 0.1316 \\
\hline
\end{tabular}

Source: our elaboration on CMM.

conditional quantile of the wage distribution, a pattern remarkably different from the other ownership types. In fact, the quantile regression coefficients are highest at the lower tail of the wage distribution and lowest at the upper tail. In that, SOEs seem to be comparatively more egalitarian in the sense that wages are more anchored to productivity at the lowest wage quantiles and less at the highest ones. We performed again the Kruskal-Wallis test on the median differences across the seven distributions for each ownership type in Figure 12. For SOEs, the null hypothesis is always rejected. The degrees of the association are statistically different across different quantiles on the conditional wage distributions. The opposite applies to foreign-, HMT-invested, shareholding and private-owned firms. Based on the Kruskal-Wallis and Dunn tests, the median are not statistically different at the $5 t h, 10 t h$ and $25 t h$ percentiles of the conditional wage distribution. Finally, the quantile regression coefficients for collective-owned enterprises display a slightly U-shaped pattern across quantiles. The link between productivity and wage is relatively higher at both the lower and the upper tails of the wage distribution, albeit there appears a much higher association at the latter tail. ${ }^{13}$

\footnotetext{
${ }^{13}$ Results are robust when estimating equation (4) for each ownership type, pooling all manufacturing firms in each own-
} 
Figure 11: Predicted wage distribution based on the estimated conditional quantile function at the 10th and $90 t h$ percentile of labour productivity distribution.
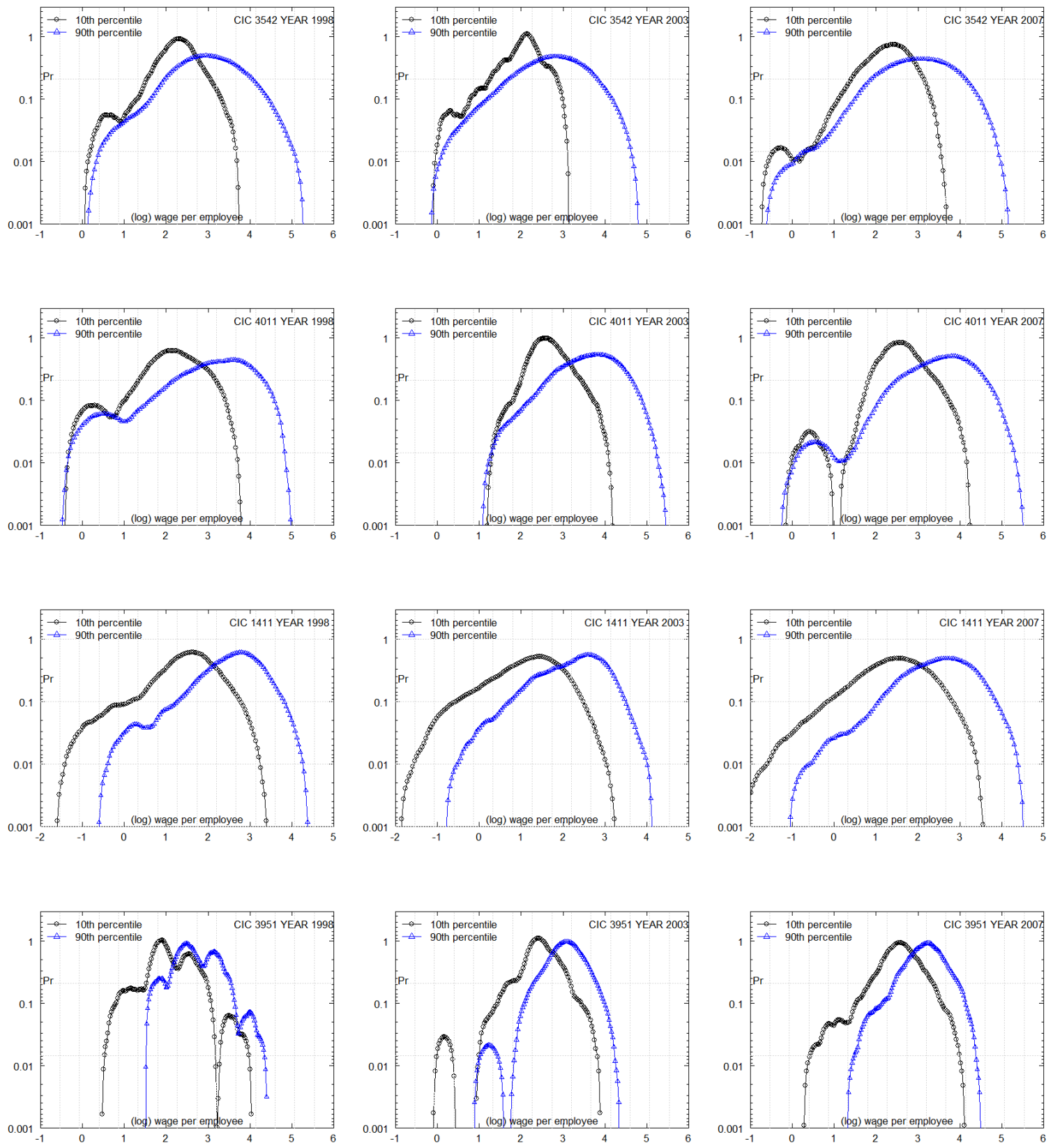

Four examples, manufacturing of gas compression machinery (CIC 3542, first row), communications transmitting equipment (CIC 4011, second row), aircrafts (CIC 1411, third row) and electrical appliances (CIC 3951, forth row) year 1998, 2003 and 2007. Note: $\log$-log scale.

In order to account for the effects of other potential determinants we estimate the following model, accounting for the role of size, age, export status and geographical location:

$$
w_{i t}=\alpha+\beta_{\tau 1} \pi_{i t}+\beta_{\tau 2} \text { size }_{i t}+\beta_{\tau 3} \text { age }_{i t}+\beta_{\tau 4} \text { export }_{i t}+\text { ownership }_{i t}+\text { geo }_{i}+y_{t}+\epsilon_{\tau i t}
$$

ership type, including 2-digit sectoral dummies. 
Figure 12: Distributions of quantile regression coefficients across four-digit sectors for each ownership type.
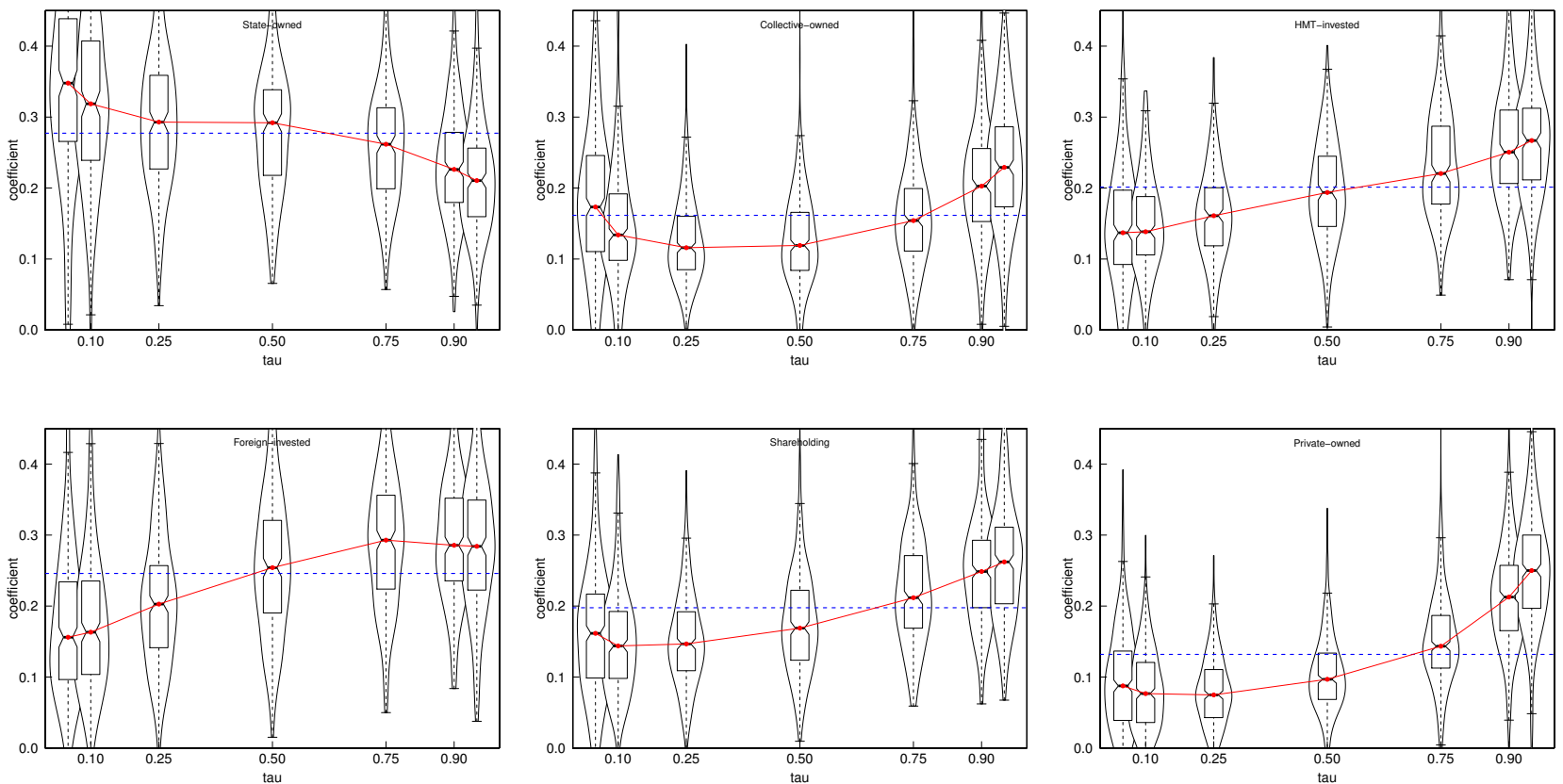

Quantile regression estimation of equation (4). The coefficient on log- labour productivity reported for the 0.05 , $0.10,0.25,0.50,0.75,0.90$ and 0.95 quantiles. Note: keeping sectors with observations $>160$. The dashed line is the median of the distribution of OLS estimates.

where $w_{i t}$, the dependent variable, is the $(\log )$ real wage per employee for firm $i$ at time $t, \pi$ the $(\log )$ labour productivity level. We control for firm's contemporaneous size (i.e., proxied by log- number of employees), age, exporting status (i.e., a time varying dummy taking value one if the firm has positive exports), ownership types and regional locations We also control for common macroeconomic shocks by including year dummies $y_{t}$.

Figure 13 shows the distribution of coefficients at each quantile of the conditional wage distribution. After performing the Wilcoxon signed-ranks test (i.e., testing the equality between the median of the distribution of estimated coefficients and zero), the Kruskal-Wallis and Dunn tests (the median differences from multiple distributions, and the post hoc pairwise comparisons) we find that the positive (median of the distribution significantly different from zero) and monotonic increasing wageproductivity nexus is robust even controlling for firm's size, age, exporting status, ownership types and geographic location. Conversely, the associations between size and wage captured by the median of the coefficient distribution of size are very different at different quantiles of the wage distribution: while it is not significantly different from zero at the $5 t h$ quantile of wage distribution, it is positive and significantly different from zero at the $10 t h, 25 t h, 50 t h$, and $75 t h$ quantiles of the wage distribution, and negative and significant in the upper tail of the wage distribution (90th and 95th quantiles). The effect of size is declining along the quantile of the wage distribution, signalling that the nexus is lower for high-wage firms rather than for low-wage ones. The association between age and wage is weakly positive and significant, slightly indicating that older firms tend to distribute higher wages, but independently from the conditional wage quantile. Moreover, there is a positive and significant association between exporting status and wage, but interestingly it is more pronounced at the lower 
Figure 13: Level model with controls, coefficients of productivity, size, age and export dummy.
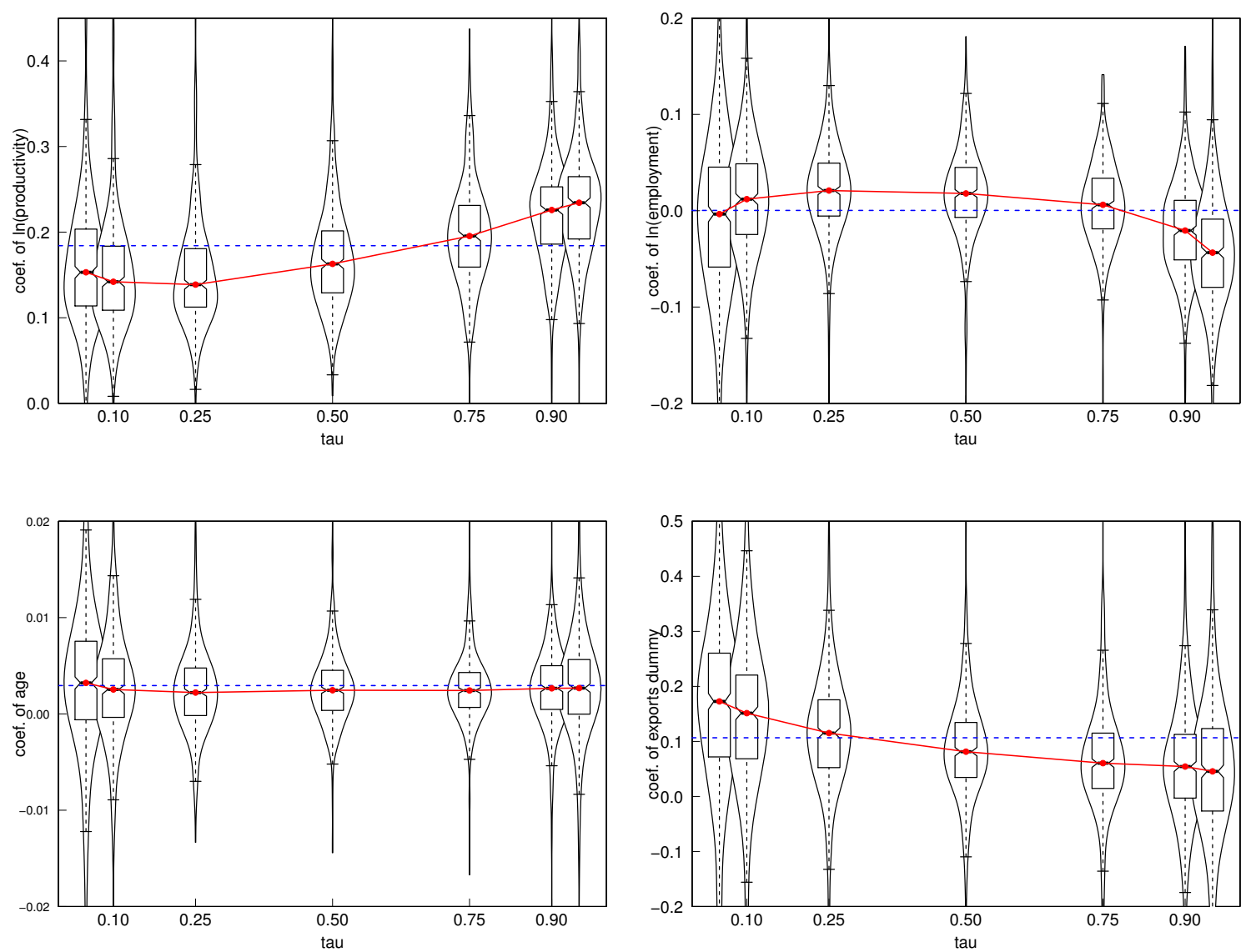

Distribution of quantile regression coefficients across 424 four-digit sectors. Note: quantile regression estimation of equation (5) for each 4-digit sector, the coefficient on log-labour productivity, log- number of employees, age and export dummy reported for the $0.05,0.10,0.25,0.50,0.75,0.90$ and 0.95 quantiles. The dashed line is the median of the distribution of OLS estimates. The median of Pseudo $R^{2}$ is 0.2067 for quantile regression.

tail of the wage distribution, and declining along quantiles. ${ }^{14}$

In terms of geographical location, all 31 provinces, autonomous regions and cities can be grouped into four regions, namely, the East region (10 provinces, including Beijing, Tianjin, Hebei, Shanghai, Jiangsu, Zhejiang, Fujian, Shandong, Guangdong, Hainan), the Middle region (6 provinces including Shanxi, Anhui, Jiangxi, Henan, Hubei, Hunan), the West region (12 provinces, including Inner Mongolia, Guangxi, Chongqing, Sichuan, Guizhou, Yunnan, Tibet, Shan'xi, Gansu, Qinghai, Ningxia, Xinjiang) and the Northeast region (3 provinces, including Liaoning, Jilin, Heilongjiang). In the regression below, we take the East region as the baseline group. Figure 14 shows the distributions of the coefficients of regional dummies. Table 7 shows the median of the distribution along the seven quantiles of the conditional wage distribution. The rank of the wage-productivity nexus from the lowest to the highest reads as Middle, North-east, West and East meaning that those firms located in the Middle, North-east and West regions transfer lower productivity gains to wages than those firms located in the East coast region. Moreover, the negative association is more pronounced at the lower-tail of the

\footnotetext{
${ }^{14}$ We also estimate model 5 for each ownership type (excluding ownership dummies). Results are confirmed and available upon request.
} 
wage distribution in Middle and North-east region. Indeed, the lower indexation rate corresponds to regions with a lower industrial concentration. In fact, as shown in Figure A.1 the spatial distribution of firms is rather uneven across the Chinese provinces. The increasing concentration in the coastal areas is associated with the heavy flows of migrant workers.

Figure 14: Coefficient of regional dummy West (left), Middle (middle), and North-east (right)
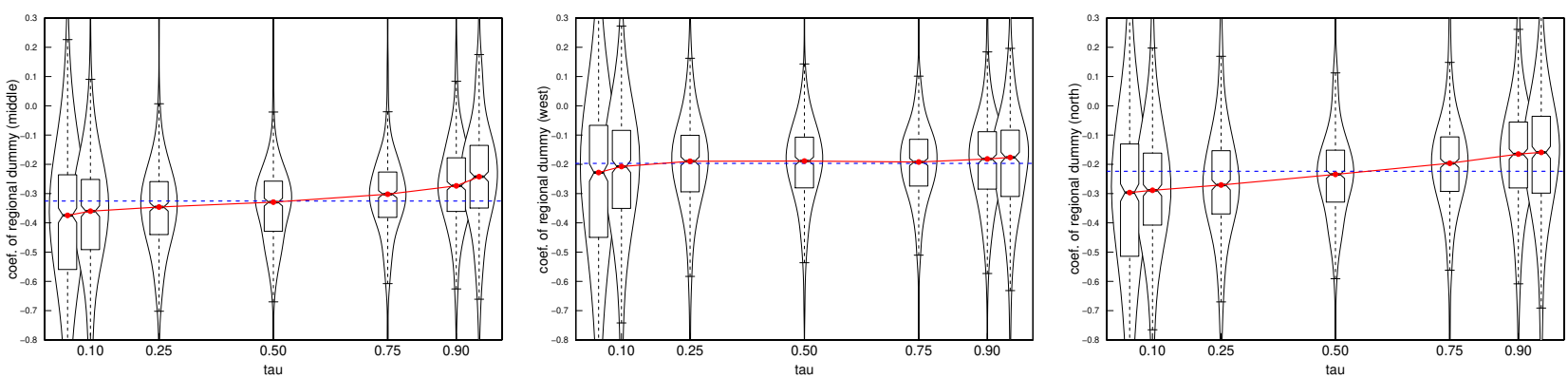

Table 7: Median of the distributions in Figure 14.

\begin{tabular}{lccccccc|c}
\hline & & \multicolumn{7}{c}{ Quantiles } \\
Region & 0.05 & 0.10 & 0.25 & 0.50 & 0.75 & 0.90 & 0.95 & OLS \\
\hline Middle & -0.375 & -0.360 & -0.346 & -0.329 & -0.302 & -0.274 & -0.242 & -0.325 \\
West & -0.228 & -0.208 & -0.190 & -0.189 & -0.192 & -0.182 & -0.176 & -0.197 \\
North-east & -0.297 & -0.289 & -0.271 & -0.235 & -0.196 & -0.165 & -0.159 & -0.224 \\
\hline
\end{tabular}

Baseline group: East region. Source: our elaboration on CMM.

\subsection{Wage growth - productivity growth}

In order to account for the dynamic structure of the nexus we estimate the relationship between wage growth and productivity growth. The values of the coefficients provide an estimate of the degree of pass-through of the latter to the former. Our model specification reads:

$$
\Delta w_{i t}=\alpha+\beta_{\tau} \Delta \pi_{i t}+y_{t}+\epsilon_{\tau i t}
$$

where $\Delta w_{i t}$ is the growth rate of wage per employee for firm $i$ at time $t$ (log difference of the wage at two consecutive years) and $\Delta \pi$ represents the growth rate of labour productivity. We also control for common macroeconomic shocks and include year dummies $y_{t} .{ }^{15}$

We estimate model (6) for each four-digit sector at the $0.05,0.10,0.25,0.50,0.75,0.90$ and 0.95 quantiles of the conditional wage growth rate distribution. Results are shown in Figure 15. First notice that elasticities are all remarkably low (less than 0.21). Moreover, unlike the estimates in levels, the pattern of the pass-through is U-shaped across quantiles. In the median interquartile range [0.25 - 0.75] of the conditional wage growth distribution, the coefficient on labour productivity growth is the lowest,

\footnotetext{
${ }^{15}$ For pooled manufacturing firms, we include 2-digit industry dummies.
} 
0.102 , that is only one tenth of labour productivity growth is passed through. Conversely, the coefficients are significantly higher in both the lower and upper tails of the wage growth distribution. ${ }^{16}$ The significance of the U-shaped pattern is confirmed by the Kruskal-Wallis and Dunn tests. Interestingly, the U-shaped patterns are independent from the type of ownership structure: Figure 16 shows the estimates of Equation (6) for each ownership type. Table 8 shows the median value of the coefficient distributions per each quantile. The significance of the U-shaped pattern at the ownership level is confirmed by the foregoing tests.

Finally, we studied at 4-digit sectoral level the predicted wage growth rates distribution at the 10 th and 90 th percentiles of the distribution of productivity growth rates. Figure 17 reports the results for two sectors, which are well representative of most of them. The Figure presents a significant overlap of the wage growth distribution: independently from being a high-growth or a low-growth productivity firm, the predicted process of wage growth is the same. The latter observation clearly militates in favour of the process of convergence presented in Section 4.

Figure 15: Distribution of quantile regression coefficients over 424 four-digit sectors.

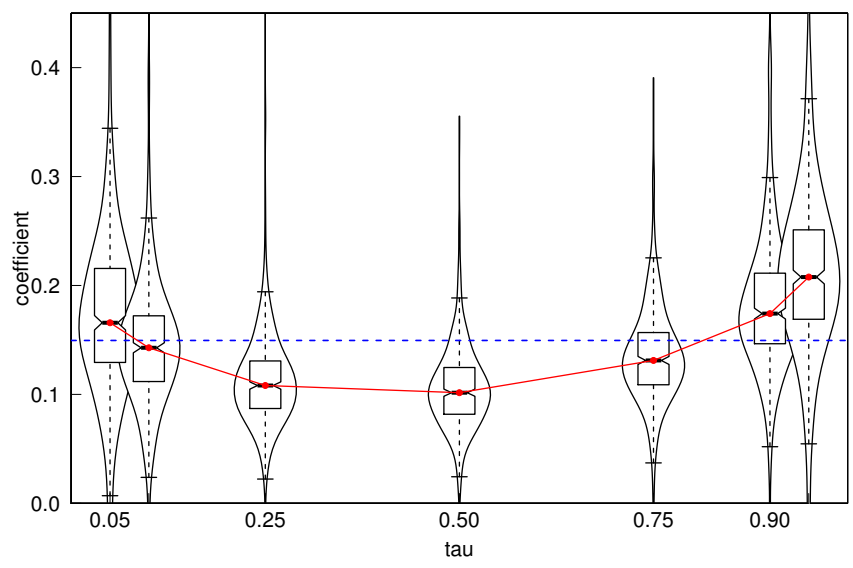

Quantile regression estimation of equation (6) for each 4-digit sector: the coefficient on growth of labour productivity reported for the $0.05,0.10,0.25,0.50,0.75,0.90$ and 0.95 quantiles. Median of Pseudo $R^{2}$ is 0.0348 . The dashed line is the median of the distribution of OLS estimates.

Table 8: Median of the distributions in Figure 16.

\begin{tabular}{lccccccc|cc}
\hline & \multicolumn{7}{c}{ Quantiles } \\
Ownership & 0.05 & 0.10 & 0.25 & 0.50 & 0.75 & 0.90 & 0.95 & OLS & Pseudo $R^{2}$ (Median) \\
\hline State-owned & 0.191 & 0.155 & 0.118 & 0.106 & 0.127 & 0.164 & 0.198 & 0.153 & 0.0580 \\
Collective-owned & 0.221 & 0.183 & 0.136 & 0.117 & 0.149 & 0.199 & 0.228 & 0.187 & 0.0535 \\
HMT-invested & 0.153 & 0.135 & 0.103 & 0.092 & 0.116 & 0.163 & 0.186 & 0.139 & 0.0502 \\
Foreign-invested & 0.134 & 0.117 & 0.086 & 0.079 & 0.104 & 0.146 & 0.169 & 0.125 & 0.0492 \\
Shareholding & 0.151 & 0.131 & 0.101 & 0.099 & 0.131 & 0.169 & 0.195 & 0.146 & 0.0496 \\
Private-owned & 0.153 & 0.137 & 0.106 & 0.108 & 0.140 & 0.178 & 0.210 & 0.150 & 0.0448 \\
\hline
\end{tabular}

Source: our elaboration on CMM.

We also estimate the growth model with controls and we perform, as usual, the Kruskal-Wallis

\footnotetext{
${ }^{16}$ We observe very similar results even when pooling all manufacturing firms, including 2-digit sectoral dummies.
} 
Figure 16: Quantile regression coefficients for each ownership type.
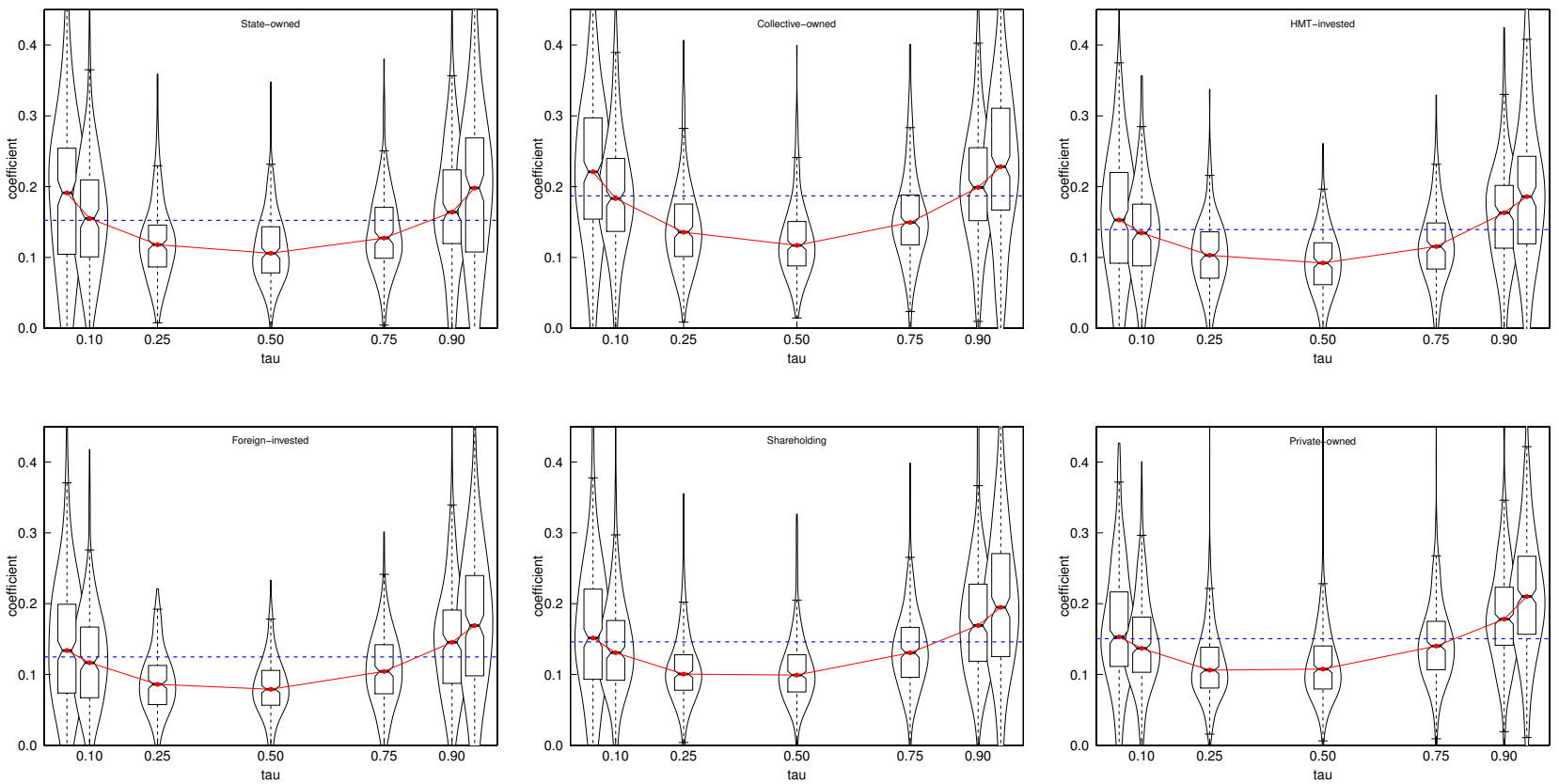

Quantile regression estimation of equation (6) pooling all manufacturing firms, including 2-digit sectoral dummies. The dashed line is the median of the distribution of OLS estimates.

Figure 17: Predicted wage growth rate distribution based on the estimated conditional quantile function at the $10 t h$ and $90 t h$ percentiles of labour productivity growth rate distribution.
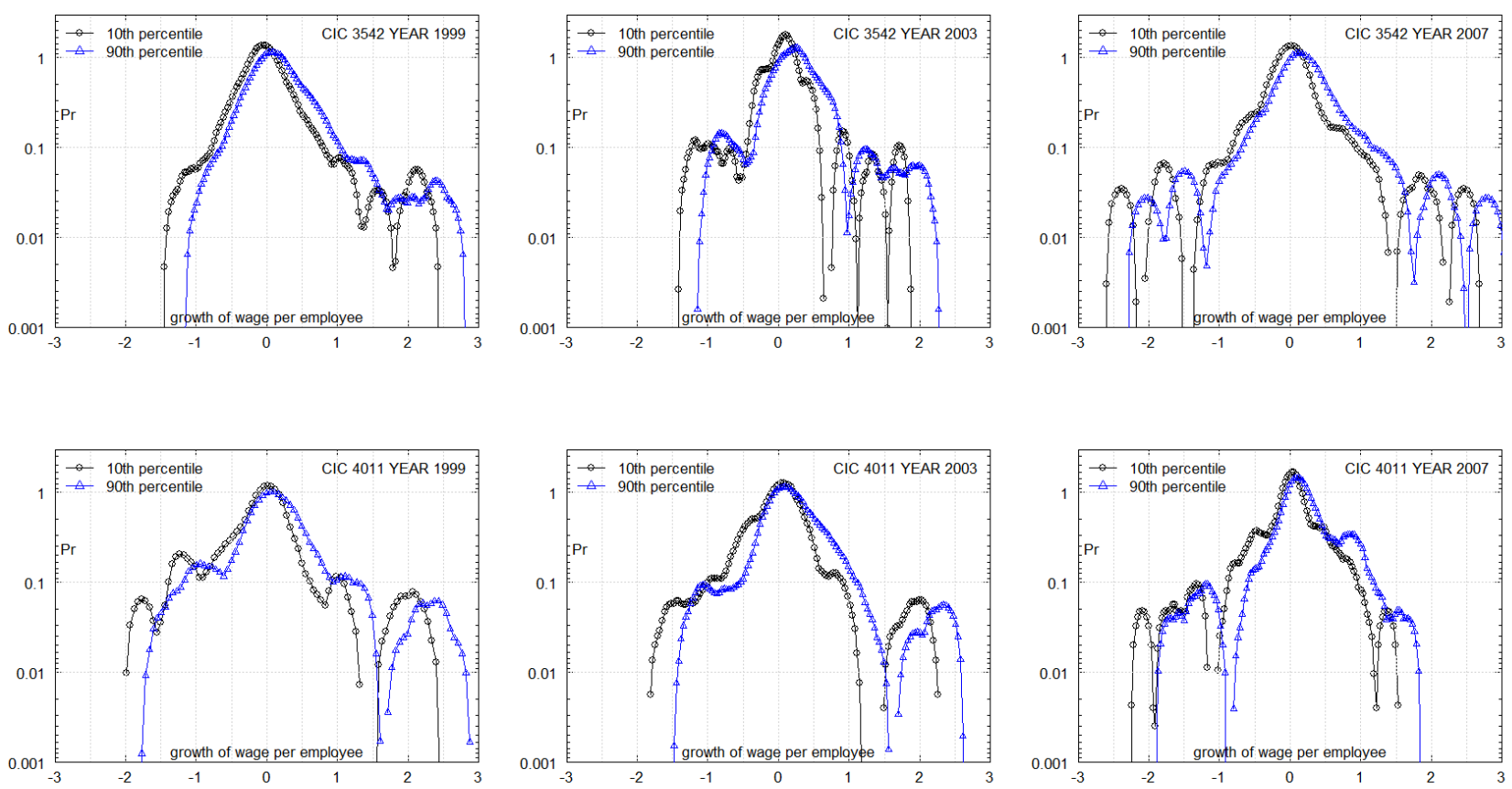

Two examples, manufacturing of gas compression machinery (CIC 3542, first row), communications transmitting equipment (CIC 4011, second rows), year 1998, 2003 and 2007. Note: y-axis in log scale. 
Figure 18: Growth model with controls, coefficients of productivity growth, size, age and export dummy.
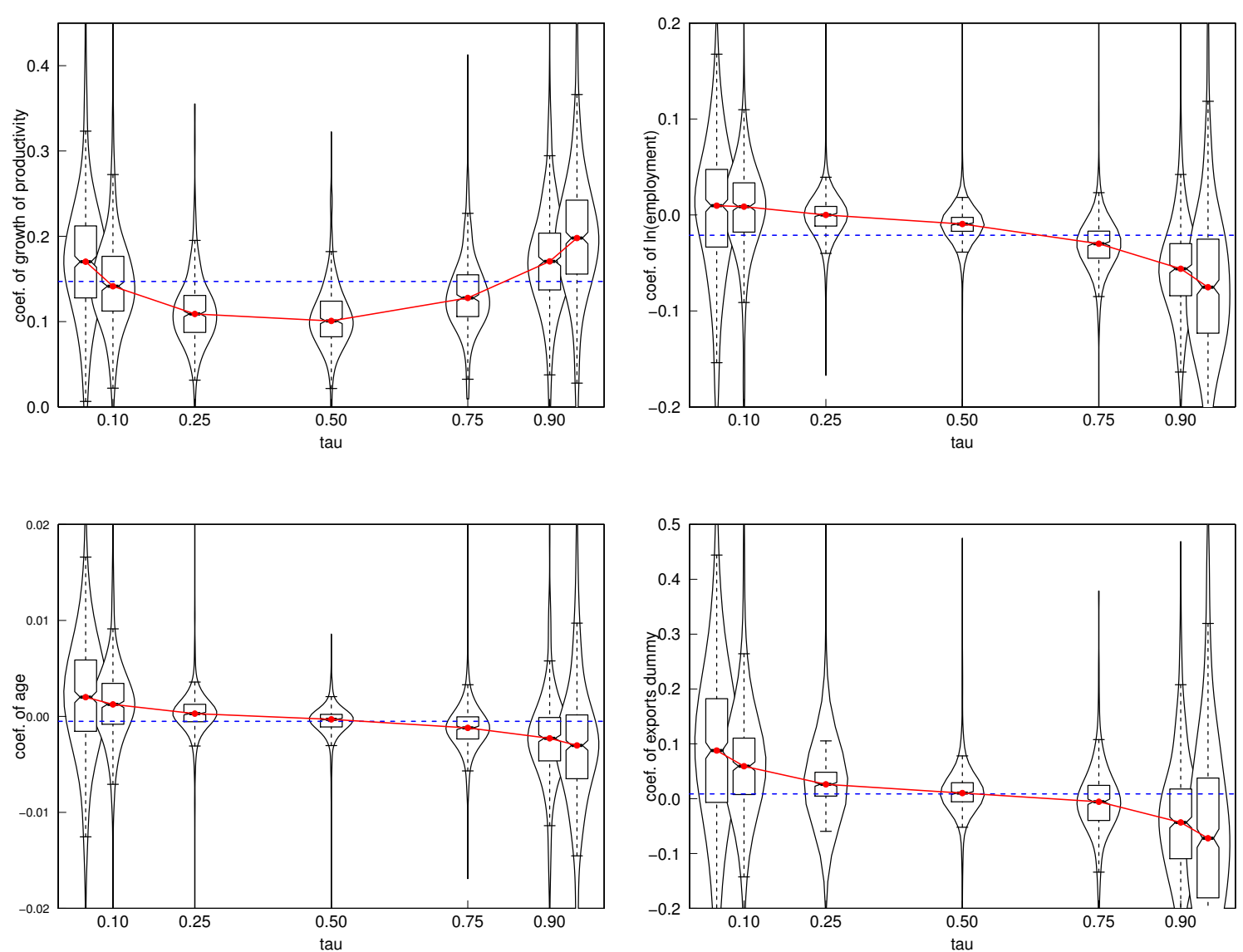

Distribution of quantile regression coefficients across 424 four-digit sectors. Note: quantile regression estimation of equation (7) for each 4-digit sector, the coefficient on log-labour productivity, log- number of employees, age and export dummy reported for the $0.05,0.10,0.25,0.50,0.75,0.90$ and 0.95 quantiles. The dashed line is the median of the distribution of OLS estimates. The median of Pseudo $R^{2}$ is 0.0519 for quantile regression.

and Dunn tests.

$$
\Delta w_{i t}=\alpha+\beta_{\tau 1} \Delta \pi_{i t}+\beta_{\tau 2} \text { size }_{i t}+\beta_{\tau 3} a_{g e} e_{i t}+\beta_{\tau 4} \text { export }_{i t}+\text { ownership }_{i t}+\text { geo }_{i}+y_{t}+\epsilon_{\tau i t}
$$

Figure 18 shows the coefficient estimates for productivity growth, size, age, and exporting status. Consistent with Figure 15, the U-shaped pattern is robust. Size displays a negative association with wage growth at the upper tail, while age has a mild decreasing monotonic pattern along the quantiles of wage growth. A similar monotonically decreasing but more pronounced pattern emerges with respect to exporting status. These aggregate findings are confirmed when decomposed by ownership structure (results available upon request).

\subsection{Dynamic quantile regression: correlated random and fixed effects estimations}

In the following we shall discuss and replicate our analysis employing the panel dimension of the data to control for unobserved heterogeneity, therefore linking quantile regression and dynamic panel techniques. In particular, we shall present the results of both the correlated random and fixed effect 
models. Abrevaya and Dahl (2008) propose to link the quantile regression estimation with correlated random effects using Chamberlain (1982) and Chamberlain (1984) approach (only for balanced panel). ${ }^{17}$ According to the correlated random effect model, $y_{i t}$ is generated by:

$$
y_{i t}=x_{i t}^{\prime} \beta+c_{i}+u_{i t}
$$

where the time invariant idiosyncratic component $c_{i}$ behaves according to:

$$
c_{i}=\phi\left(x_{i}\right)+v_{i}, \quad E\left(v_{i} \mid x_{i}\right)=0
$$

For any $\tau \in[0,1]$, the conditional quantile function of $y_{i t}$ is:

$$
Q_{\tau}\left(y_{i t} \mid x_{i}\right)=x_{i t}^{\prime} \beta+Q_{\tau}\left(v_{i}+u_{i t} \mid x_{i t}\right)+\phi\left(x_{i}\right)
$$

assuming that $v_{i}$ is orthogonal to $x_{i}$ and allowing for the heteroschedasticity of $x_{i}$, that is $Q_{\tau}\left(u_{i t} \mid x_{i}, v_{i}\right)=$ $Q_{\tau}\left(u_{i t} \mid x_{i t}\right)$ we have the final specification for the quantile regression with a correlated random effect estimation:

$$
\mathrm{Q}_{\tau}\left(y_{i t} \mid x_{i t}\right)=x_{i t}^{\prime} \beta_{\tau}+\phi\left(x_{i}\right)
$$

where

$$
x_{i t}^{\prime} \beta_{\tau}=x_{i t}^{\prime} \beta+Q_{\tau}\left(v_{i}+u_{i t} \mid x_{i t}\right)
$$

with $\phi\left(x_{i}\right)$, in the case of balanced panel, being:

$$
\phi\left(x_{i}\right)=\psi_{\tau}^{t}+x_{i 1}^{\prime} \lambda_{\tau}^{1}+\ldots+x_{i T}^{\prime} \lambda_{\tau}^{T}
$$

or alternatively for an unbalanced panel we have $\phi\left(x_{i}\right)=\psi_{\tau}^{t}+\overline{x_{i}^{\prime}} \lambda_{\tau}$ (Mundlak, 1978). In the following, we estimate a wage level - productivity level quantile regression with a correlated random effect, according to such an approach, as our panel is not balanced.

Figure 19 shows the results for the correlated random effect model (CREM) which accounts for the dynamic evolution of idiosyncratic productivity over time, according to the specification of Equation 10. That is, the estimates of the wage-productivity nexus consider the micro dynamics of productivities. According to this procedure, the coefficients do not show any significant difference among quantiles at the aggregate level. Conditioning on the productivity gains the pass-through is completely flat. However, when disaggregating by ownership structure, the quantile regression with correlated random effects confirms the same pattern obtained in the pooled analysis for SOEs, as shown in Figure B.6 and Table 9, with a declining pass-through across wage quantiles, but differently from the pooled estimates, an almost constant pass-through for the rest of ownership types.

An alternative specification to treat unobserved heterogeneity is the fixed effects estimator, according to Koenker (2004)'s method. The method, which proposes a penalizing estimator, imposes that the effect of the unobserved time-invariant characteristics of the firm has to be the same at each quantile

\footnotetext{
${ }^{17}$ The pooled quantile regression employed the panel structure of the data only for computing standard errors. Since each firm appears at least once in the data, the clustered sampling bootstrap is used. Being present dependence within firm's indicators over years, the standard asymptotic-variance formula (Koenker and Bassett Jr, 1978) and the standard bootstrap approach, both based upon independent observations, should not be applied. Hence, instead, a given bootstrap sample is created by repeatedly drawing (with replacement) a firm from the sample of $M$ firms and including all its measures (over years), where the draws continue until the desired bootstrap sample size is reached.
} 
Figure 19: Model in level - CREM.

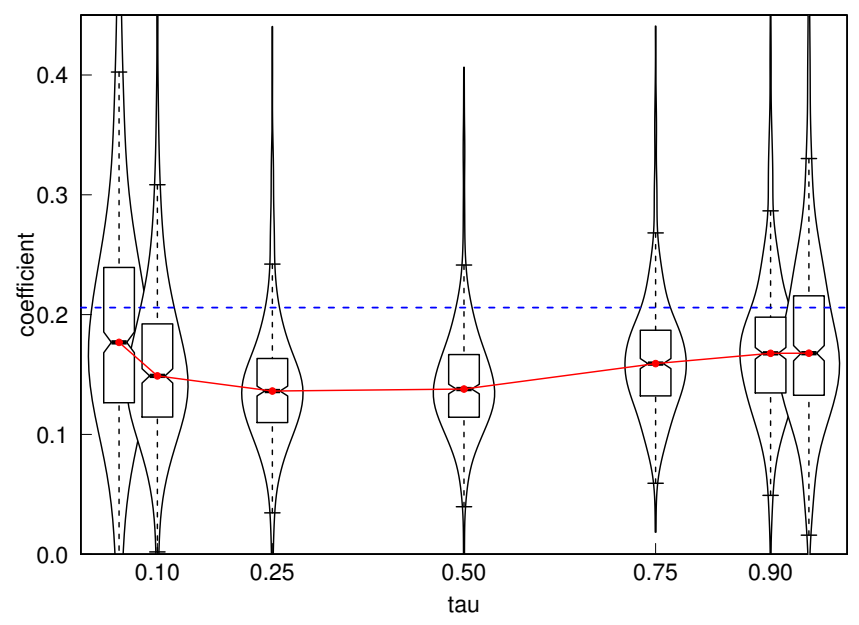

Distribution of quantile regression coefficients across 424 four-digit sectors. Note: quantile regression estimation of equation (4) for each 4-digit sector, the coefficient on log- labour productivity reported for the $0.05,0.10,0.25$, $0.50,0.75,0.90$ and 0.95 quantiles. The dashed line is the median of the distribution of OLS estimates. The median of Pseudo $R^{2}$ is 0.1454 for quantile regression.

Table 9: Model in level - CREM.

\begin{tabular}{lcccccccc}
\hline & \multicolumn{7}{c}{ Quantiles } \\
Ownership & 0.05 & 0.10 & 0.25 & 0.50 & 0.75 & 0.90 & 0.95 & Pseudo $R^{2}$ (Median) \\
\hline State-owned & 0.261 & 0.232 & 0.192 & 0.165 & 0.144 & 0.123 & 0.119 & 0.1867 \\
Collective-owned & 0.243 & 0.181 & 0.146 & 0.134 & 0.152 & 0.186 & 0.204 & 0.1262 \\
HMT-invested & 0.156 & 0.134 & 0.126 & 0.130 & 0.141 & 0.157 & 0.170 & 0.1526 \\
Foreign-invested & 0.143 & 0.128 & 0.126 & 0.125 & 0.134 & 0.120 & 0.118 & 0.1538 \\
Shareholding & 0.164 & 0.148 & 0.142 & 0.140 & 0.147 & 0.163 & 0.171 & 0.1461 \\
Private-owned & 0.132 & 0.117 & 0.112 & 0.117 & 0.141 & 0.173 & 0.205 & 0.1343 \\
\hline
\end{tabular}

Median of the distributions in Figure B.6. Source: our elaboration on CMM. 


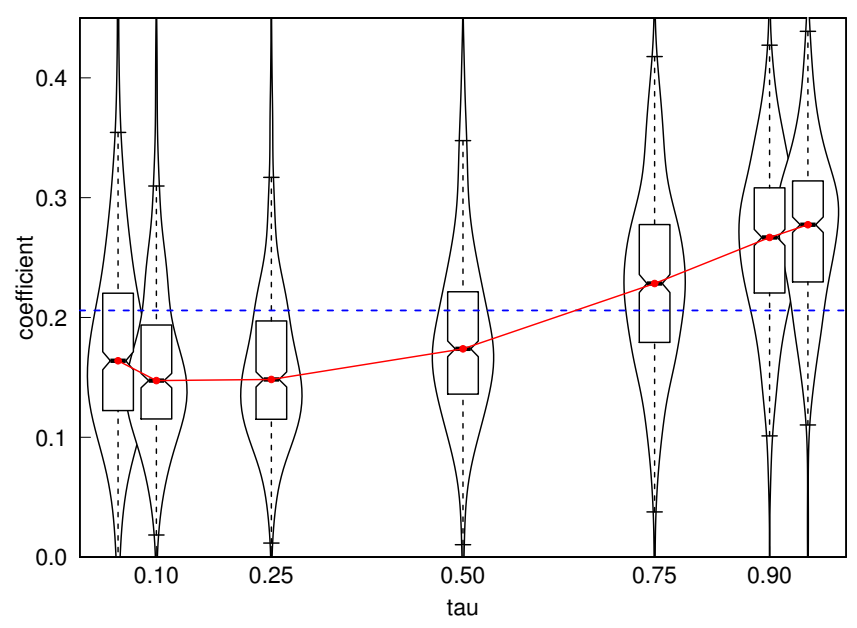

Distribution of quantile regression coefficients across 424 four-digit sectors. Note: quantile regression estimation of equation (4) for each 4-digit sector, the coefficient on log- labour productivity reported for the $0.05,0.10,0.25$, $0.50,0.75,0.90$ and 0.95 quantiles. The dashed line is the median of the distribution of OLS estimates. The median of Pseudo $R^{2}$ is 0.1471 for quantile regression.

$\tau$, according to the specification:

$$
\mathbf{Q}_{\tau}\left(y_{i t} \mid x_{i t}\right)=\alpha_{i}+x_{i t}^{\prime} \beta_{\tau}
$$

In this case the fixed effect is a "locational shift", not affected by the quantile. Figure 20 shows the distribution of coefficient estimates using the fixed-effects method. The FE quantile regression estimation does confirm the same pattern emerging from the pooled analysis at the aggregate level: wage dispersion increases with productivity, with an estimated magnitude of the coefficient rather similar to the pooled quantile regression. Again, similarly to the pooled analysis, when accounting for the ownership structure, SOEs show a declining pass-through along the distribution, while the opposite occurs for the rest, as shown in Figure B.6. The different results provided by the CREM and the FE highlight that the pass-through of productivity gains turns out to be flat when accounting for the dynamics of firm-level productivities (CREM), washing out the apparent increasing pattern revealed by the FE estimators. In this respect, given the impressive process of productivity catching-up, the CREM reveals to be more appropriate to explicitly capture the degree of pass-through.

Finally, as a robustness test, we check the growth specification with both CREM and FE. As shown in Figure 21 in both cases the dynamic quantile specifications closely follow the model in first-differences (growth model), as expected.

\subsection{Variance of wage and variance of productivity}

In order to further study the relationship between wage and productivity dispersion, let us estimate the association between the variance of log-wage and of log-labour productivity across firms in the same 4-digit sector according to the following model: 
Table 10: Model in level - FE.

\begin{tabular}{lcccccccc}
\hline & \multicolumn{7}{c}{ Quantiles } \\
Ownership & 0.05 & 0.10 & 0.25 & 0.50 & 0.75 & 0.90 & 0.95 & Pseudo $R 2$ (Median) \\
\hline State-owned & 0.347 & 0.323 & 0.296 & 0.283 & 0.260 & 0.227 & 0.211 & 0.1858 \\
Collective-owned & 0.183 & 0.144 & 0.121 & 0.126 & 0.155 & 0.206 & 0.229 & 0.1327 \\
HMT-invested & 0.144 & 0.138 & 0.158 & 0.186 & 0.219 & 0.249 & 0.262 & 0.1550 \\
Foreign-invested & 0.157 & 0.163 & 0.202 & 0.243 & 0.281 & 0.283 & 0.277 & 0.1554 \\
Shareholding & 0.166 & 0.144 & 0.147 & 0.170 & 0.214 & 0.249 & 0.259 & 0.1488 \\
Private-owned & 0.091 & 0.078 & 0.076 & 0.097 & 0.144 & 0.213 & 0.250 & 0.1362 \\
\hline
\end{tabular}

Median of the distributions in Figure B.6. Source: our elaboration on CMM.

Figure 21: Model in growth - CREM (left), FE (right).
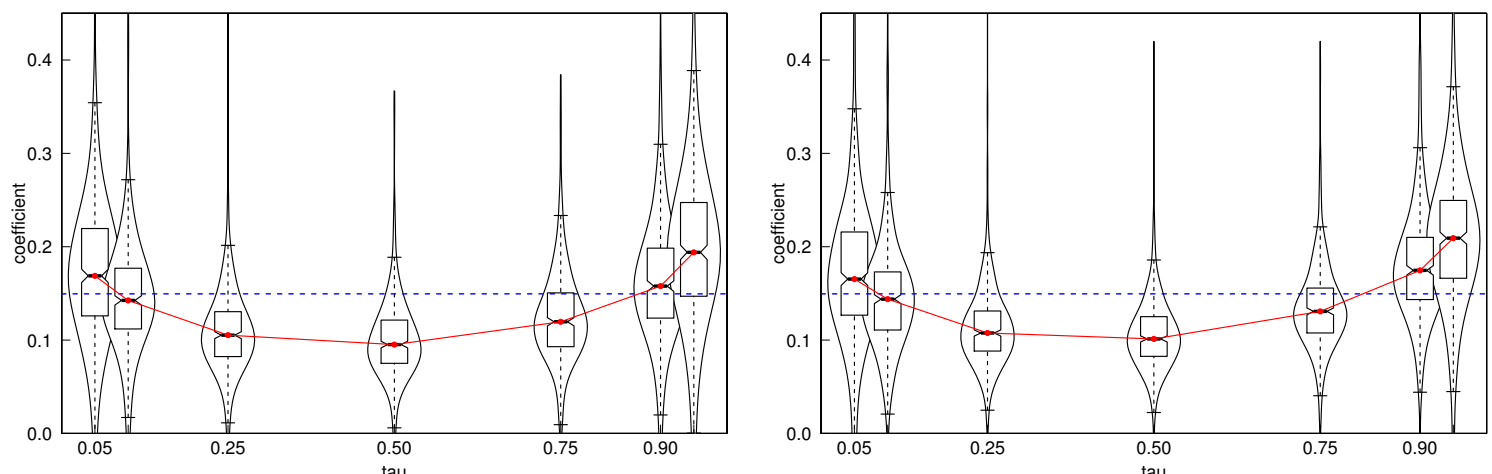

Distributions of quantile regression coefficients across 424 four-digit sectors. Note: quantile regression estimation of equation (6) for each 4-digit sector, the coefficient on growth of labour productivity reported for the 0.05 , $0.10,0.25,0.50,0.75,0.90$ and 0.95 quantiles. The dashed line is the median of the distribution of OLS estimates. The median of Pseudo $R^{2}$ is 0.0361 (CREM) and 0.0371 (FE) for quantile regression. 
Figure 22: Quantile regression coefficients.

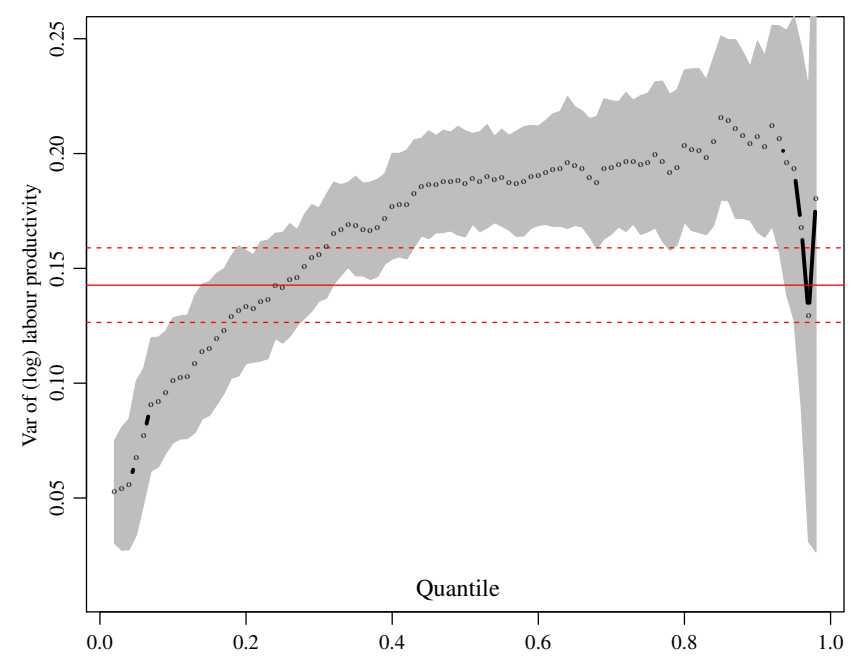

Quantile regression estimation of equation (15) pooling all 4-digit sectors, including 2-digit sectoral dummies. The solid line is the OLS estimate. Bootstrapped standard errors with $90 \%$ confidence band. Pseudo $R^{2}$ is 0.1969 for quantile regression at the 0.50 quantile.

$$
\operatorname{VAR} w_{j t}=\alpha+\beta_{\tau} \operatorname{VAR} \pi_{j t}+y_{t}+\epsilon_{\tau j t}
$$

where VAR $w_{j t}$ is the variance of wage per employee (across firms) for sector $j$ (at 4-digit level) at time $t$, and $\operatorname{VAR} \pi_{j t}$ is that of labour productivity level. The model allows to capture the extent to which wage dispersion at the sectoral level is affected by between-firms productivity dispersion. Similar OLS models have been estimated in Berlingieri et al. (2017) for a cross-country analysis. However, the quantile approach allows the study of the link between wage and productivity dispersion along the conditional distribution of between-firms wage dispersions. Figure 22 shows the quantile compared with the OLS estimates (horizontal solid line). The OLS coefficient is around 0.15 . The monotonically increasing quantile pattern indicates that the higher the sectoral level wage dispersion, the higher is the contribution of sectoral productivity dispersion on it. Figure B.8 shows the quantile regression and the OLS estimates (horizontal solid line) for each ownership type. The foregoing pattern is confirmed independently from the ownership structure. Note that if the generating process of wages were identical across all wage quantiles one would not observe any correlation between variances of productivity and variances in wages.

\subsection{Variance of wages and mean of productivities}

Yet another set of analysis aims at detecting whether the average productivity performance of the sector might affect between-firms wage dispersion, and the extent to which this might vary from less to more dispersed wage sectors. In so doing, we indirectly detect whether the wage formation mechanism is affected by some industry productivity performance. Therefore, we estimate the following model: 
Figure 23: Quantile regression coefficients.

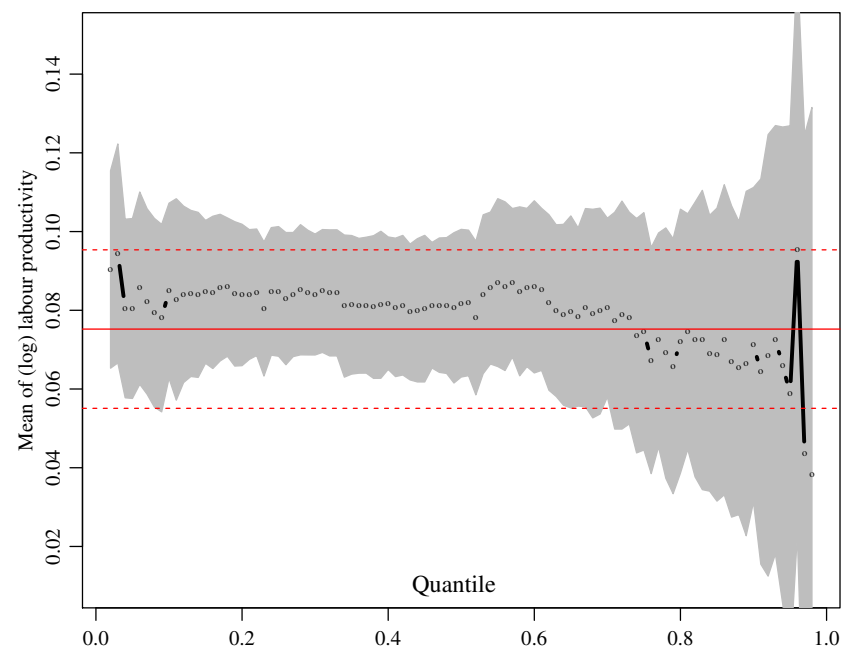

Quantile regression estimation of equation (16) pooling all 4-digit sectors, including 2-digit sectoral dummies. The solid line is the OLS estimate. Bootstrapped standard errors with $90 \%$ confidence band. Pseudo $R^{2}$ is 0.1629 for quantile regression at the 0.50 quantile.

$$
\operatorname{VAR} w_{j t}=\alpha+\beta_{\tau} \operatorname{MEAN} \pi_{j t}+y_{t}+\epsilon_{\tau j t}
$$

where VAR $w_{j t}$, the dependent variable, is the variance of wage per employee (across firms) for sector $j$ (at 4-digit level) at time $t$. MEAN $\pi_{j t}$ represents the sectoral mean of labour productivity level.

Figure 23 shows the quantile regression estimates (dashed curve) and the OLS estimate (horizontal solid line), where the OLS coefficient is around 0.075, while Figure B.9 presents the same estimation for each ownership type. At the aggregate level the quantile regression analysis is redundant as the quantile coefficients and the OLS ones are largely overlapping. However when decomposing for the ownership structure, SOEs present a negative relationship, decreasing along quantiles, meaning that the average productivity performance of the industry exerts an equalizing effect on wage dispersion between firms, the higher the degree of wage dispersion in the given sector. The opposite occurs for the rest of the ownership types, presenting either a positive and increasing relationship along the distribution, as in the case of foreign firms (HMTs and foreign-invested enterprises), or an almost null and flat one, as in the case of domestic firms. It has to be noted that the difference with the OLS estimates loses significance for the highest quantiles in all three cases (SOEs, HMTs, foreign-invested enterprises).

\section{Theoretical interpretation}

Overall, the results presented above militate in favour of the presence of two co-existing regimes of wage formation. A first one characterizing State Owned enterprises hints at the fact that firm-level wages $\left(w_{i_{S O}}\right)$ are (partly) indexed on the average productivity level of the industry $\left(\bar{\pi}_{S O}\right)$ rather than on the firm level one: Equation 17 captures the idea, illustrated in Figure 24.A. This implies that the pass-through is declining along the inverse of the rank of productivity distributions (cf. Equation 18 
and Figure 24.B): the lower the productivity level, the higher the pass-through $(\gamma)$, and the other way round.

Conversely, the wage-setting process occurring in all the rest of the firms seems rather different: it entails that wages $\left(w_{i_{P O}}\right)$ are (quite partially) indexed on firm level-productivity $\left(\pi_{i_{P O}}\right)$. Therefore wages increase in some proportion to firm-level productivity increases (cf. Equation 19 and see Figure 24.C) resulting into a constant pass-through along the entire productivity range of the firms (Equation 20 and Figure 24.D), independently from firms absolute ranking in terms of productivity.

$$
\begin{gathered}
w_{i_{S O}}=f\left(\bar{\pi}_{S O}\right) \Rightarrow \Delta w_{i_{S O}}=g\left(\Delta \bar{\pi}_{S O}\right) \\
\frac{\Delta w_{i_{S O}}}{\Delta \pi_{i_{S O}}}=h(\text { inverse prod. rank }) \\
w_{i_{P O}}=f\left(\pi_{i_{P O}}\right) \Rightarrow \Delta w_{i_{P O}}=g\left(\Delta \pi_{i_{P O}}\right) \\
\frac{\Delta w_{i_{P O}}}{\Delta \pi_{i_{P O}}}=h(\text { inverse prod. rank })
\end{gathered}
$$

All that, in turns, entails an underlying equalizing effect on the wage/productivity nexus. In a way, it seems that SOEs bear still some "fossil traits" of the older Central Planning period, and also the strongest resemblance to the regime of wage determination characterizing the "Golden Age" of Western post-WWII capitalist growth. Conversely, the other governance forms appear to be much more market-driven. In terms of the underlining institutions governing the labour markets, our results show clearly the absence of a collective negotiation process and the presence of firm-based distributional mechanisms in the private sector. There is indeed a unique trade union, All-China Federation of Trade Unions (ACFTU), which however acts largely as a corporate "human-resource department" (Kuruvilla, 2018). On top of that, the role of migrant workers has been acknowledged as crucial, entailing an almost unlimited supply of labour (Ngai and Huilin, 2010). Unfortunately our dataset does not allow to look at worker flows, but the evidence reported in Figure A.1 confirms the increasing concentration of manufacturing firms in coastal areas, where workers from the interior migrate.

The coexistence of two regimes of wage setting is also related to the processes of internal corporate restructuring and of exposition to international global value chains. Concerning the former, Autor A have highlighted the "creative restructuring" of state-owned enterprises with those belonging to strategic, highly-innovative sectors remaining under the hat of the State, maintaining more egalitarian and market-resilient forms of value distribution to workers. Concerning the latter, private firms have been those more inserted into global value chains, therefore less keen to pass their gains on workers. The Foxconn case is almost an archetype (Chan and Pun, 2010), among the biggest worldwide employers and leading Chinese exporter. Its hiring strategy has been mainly taking advantage of the massive migration from agricultural areas of young workers (born after 1980s). The firm is part of an international division of production and a value chain which sees its customers (Apple, Dell, Microsoft) squeezing its margins. Correspondingly in order to secure contracts, Foxconn minimizes costs, and transfers the pressure of low profit margins to front-line workers. Workers are paid at an average wage quite close to the province minimum, massively relying upon overtime hours. 

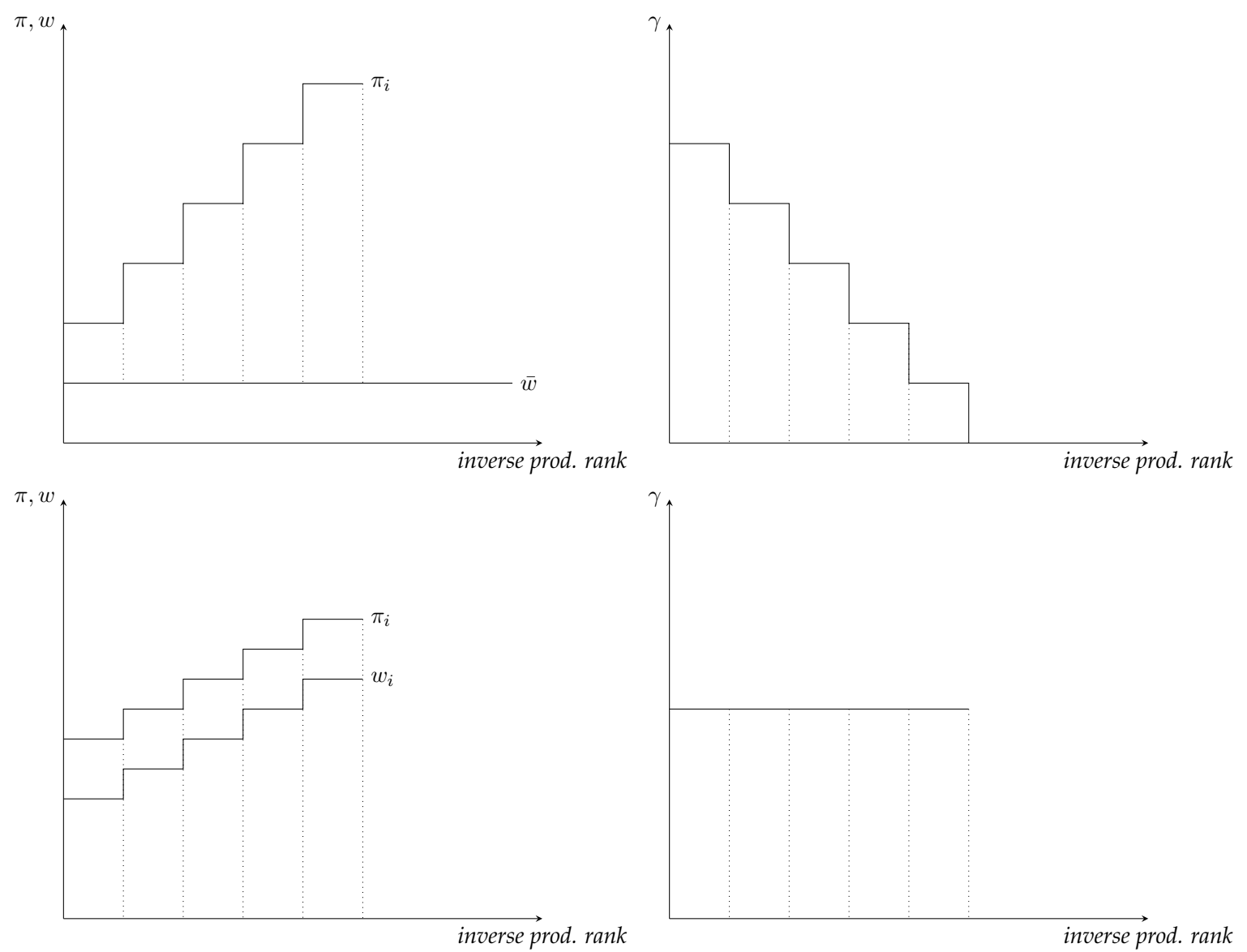

Figure 24: Top panel (State-Owned enterprises): A. The wage-productivity nexus (left); B. The ensuing passthrough (right).

Bottom panel (Private-Owned enterprises): C. The wage-productivity nexus (left); D. The ensuing pass-through (right) 


\section{Conclusions}

Using a detailed firm-level dataset which includes all industrial firms above some minimum threshold over the period 1998-2007, distinguishing also the ownership types of the firms (e.g., State-owned, foreign MNCs, private-owned, etc.), we investigate the inter-sectoral and inter-institutional heterogeneity in both wage and productivity distributions and the coupled dynamics of the two variables, both in levels and rates of growth. Our results show a process of convergence both in productivity and wage distributions driven by a declining 50-10 percentile ratio. When decomposing the variance in terms of within and between sectoral variations, the within sectoral component accounts for more than $80 \%$ of the total variation. However, while the within sectoral dispersion in productivity shrinks, the wage one remains almost stable. We then perform quantile regressions, trying to control for different wage-productivity relations over the quantiles of the distributions. And we further refine the analysis with correlated random effects and fixed effects quantile estimations to explicitly account for the panel structure of our dataset.

A few results are quite robust under different estimation strategies. First, throughout the impressive Chinese economic miracle, elasticities of real wages to productivities - that is the ratios of rates of variations of the former to the latter - are always positive both under pooled and longitudinal estimates, both at firm- and sectoral-levels. Second, such elasticities are remarkably low, and decreasing in many sub-periods since the late seventies. The foregoing stylised facts, taken together, suggest that China has never experienced a pure Lewis-Marx stage of early industrialization whereby an "unlimited supply of labour" has kept wages at some subsistence level with labour productivity exponentially growing. The low elasticities of wages to productivity are plausibly the consequence of the massive flow of migrant workers from the rural areas to the coasts, somewhat resembling the early phase of the English Industrial Revolution with the pattern of enclosure in the country-side and massive migrations to the industrial towns. However, even in the manufacturing sector, the distribution of gains from the impressive labour productivity growth appears to be markedly uneven. Recall that our evidence suggests that, at best, a $1 \%$ increase in productivity translates into $0.3 \%$ increase in real wages, which is markedly lower than in developed countries. Finally, third, governance institutions seem to matter a lot. So, most ownership types display (very low) firm-specific, positive elasticities of real wages to productivities. Conversely, State-owned enterprises show higher elasticities and exert an equalizing role, with a declining pass-through along the wage distribution.

\section{References}

Abrevaya, J. and C. M. Dahl (2008). The effects of birth inputs on birthweight: evidence from quantile estimation on panel data. Journal of Business E Economic Statistics 26(4), 379-397.

Appleton, S., L. Song, and Q. Xia (2014). Understanding urban wage inequality in China 1988-2008: Evidence from quantile analysis. World Development 62, $1-13$.

Barth, E., A. Bryson, J. C. Davis, and R. Freeman (2016). It's where you work: Increases in the dispersion of earnings across establishments and individuals in the United States. Journal of Labor Economics 34(S2), S67-S97. 
Berlingieri, G., P. Blanchenay, and C. Criscuolo (2017). The great divergence (s). Technical report, OECD Science, Technology and Industry Policy Papers, No. 39, OECD Publishing, Paris.

Bhattacharya, M., P. K. Narayan, S. Popp, and B. N. Rath (2011). The productivity-wage and productivity-employment nexus: a panel data analysis of indian manufacturing. Empirical Economics 40(2), 285-303.

Brandt, L., J. Van Biesebroeck, and Y. Zhang (2012). Creative accounting or creative destruction? firm-level productivity growth in Chinese manufacturing. Journal of Development Economics 97(2), 339-351.

Card, D., A. R. Cardoso, J. Heining, and P. Kline (2018). Firms and labor market inequality: Evidence and some theory. Journal of Labor Economics 36(S1), S13-S70.

Chamberlain, G. (1982). Multivariate regression models for panel data. Journal of econometrics 18(1), $5-46$.

Chamberlain, G. (1984). Panel data. Handbook of econometrics 2, 1247-1318.

Chan, J. and N. Pun (2010). Suicide as protest for the new generation of chinese migrant workers: Foxconn, global capital, and the state. Asia-Pacific journal: Japan focus 37(2), 1-50.

Dinno, A. (2015). Nonparametric pairwise multiple comparisons in independent groups using Dunn's test. Stata Journal 15, 92-300.

Dong, X.-Y. (2005). Wage inequality and between-firm wage dispersion in the 1990s: A comparison of rural and urban enterprises in China. Journal of Comparative Economics 33(4), 664 - 687.

Dosi, G., D. Moschella, E. Pugliese, and F. Tamagni (2015, Oct). Productivity, market selection, and corporate growth: comparative evidence across us and europe. Small Business Economics 45(3), 643672.

Dunne, T., L. Foster, J. Haltiwanger, and K. R. Troske (2004). Wage and productivity dispersion in united states manufacturing: The role of computer investment. Journal of Labor Economics 22(2), 397-429.

Fang, C. and D. Yang (2011). Wage increases, wage convergence, and the Lewis turning point in China. China economic review 22(4), 601-610.

Haans, R. F., C. Pieters, and Z.-L. He (2016). Thinking about u: Theorizing and testing u-and inverted u-shaped relationships in strategy research. Strategic Management Journal 37(7), 1177-1195.

Han, J., R. Liu, and J. Zhang (2012). Globalization and wage inequality: Evidence from urban China. Journal of International Economics 87(2), 288 - 297.

Hau, H., Y. Huang, and G. Wang (2016). Firm response to competitive shocks: Evidence from China's minimum wage policy. Research Paper 16-47, Swiss Finance Institute.

Jefferson, G., A. Hu, X. Guan, and X. Yu (2003). Ownership, performance, and innovation in China's large and medium- size industrial enterprise sector. China Economic Review, Elsevier 14(1), 89-113. 
Katovich, E. S. and A. G. Maia (2018). The relation between labor productivity and wages in brazil: a sectoral analysis. Nova Economia 28(1), 7-38.

Koenker, R. (2004). Quantile regression for longitudinal data. Journal of Multivariate Analysis 91(1), 74-89.

Koenker, R. (2005). Quantile Regression. Econometric Society Monographs. Cambridge University Press.

Koenker, R. and G. Bassett Jr (1978). Regression quantiles. Econometrica 46(1), 33-50.

Koenker, R. and K. F. Hallock (2001, December). Quantile regression. Journal of Economic Perspectives 15(4), 143-156.

Kruskal, W. H. and W. A. Wallis (1952). Use of ranks in one-criterion variance analysis. Journal of the American statistical Association 47(260), 583-621.

Kuruvilla, S. (2018). Editorial essay: From cautious optimism to renewed pessimism: Labor voice and labor scholarship in china. ILR Review 71(5), 1013-1028.

Mayneris, F., S. Poncet, and T. Zhang (2018). Improving or disappearing: Firm-level adjustments to minimum wages in china. Journal of Development Economics 135, 20-42.

Mergulhão, A. and J. A. Pereira (2019). Productivity-wage nexus: distributional approach on firms in portugal. Working paper 3/2019, GPEARI / Ministry of Finance.

Mundlak, Y. (1978). On the pooling of time series and cross section data. Econometrica 46(1), 69-85.

Ngai, P. and L. Huilin (2010). Unfinished proletarianization: self, anger, and class action among the second generation of peasant-workers in present-day china. Modern China 36(5), 493-519.

Pessoa, J. P. and J. Van Reenen (2013). Decoupling of wage growth and productivity growth?: Myth and reality. Technical report, CEP Discussion Paper No 1246.

Schmitt, J. (2013). Why does the minimum wage have no discernible effect on employment. Discussion paper, Center for Economic and Policy Research, Washington DC.

Schwellnus, C., A. Kappeler, and P.-A. Pionnier (2017). Decoupling of wages from productivity. Technical report, OECD Economics Department Working Papers, No. 1373, OECD Publishing, Paris.

Stansbury, A. M. and L. H. Summers (2017). Productivity and pay: Is the link broken? Technical report, National Bureau of Economic Research.

Syverson, C. (2017, May). Challenges to mismeasurement explanations for the US productivity slowdown. Journal of Economic Perspectives 31(2), 165-86.

Wakeford, J. (2004). Productivity, wages and employment in south africa's manufacturing sector, 19702002. Working pa per 04/85, Development Pol icy Re search Unit, University of Cape Town.

Xia, Q., L. Song, S. Li, and S. Appleton (2014). The effect of the state sector on wage inequality in urban China: 1988-2007. Journal of Chinese Economic and Business Studies 12(1), 29-45. 
Table A.1: Aggregation of the 23 registration categories. Source: Jefferson et al. (2003), Annex I.

\begin{tabular}{|c|c|c|c|c|}
\hline Code & Ownership category & & Code & Registration status \\
\hline \multirow[t]{3}{*}{1} & \multirow{3}{*}{\multicolumn{2}{|c|}{ State-owned }} & 110 & State-owned enterprises \\
\hline & & & 141 & State-owned jointly operated enterprises \\
\hline & & & 151 & Wholly State-owned companies \\
\hline \multirow[t]{3}{*}{2} & \multirow{3}{*}{\multicolumn{2}{|c|}{ Collective-owned }} & 120 & Collective-owned enterprises \\
\hline & & & 130 & Shareholding cooperatives \\
\hline & & & 142 & Collective jointly operated enterprises \\
\hline \multirow[t]{4}{*}{3} & \multirow{4}{*}{\multicolumn{2}{|c|}{ Hong Kong, Macao, Taiwan-invested }} & 210 & Overseas joint ventures \\
\hline & & & 220 & Overseas cooperatives \\
\hline & & & 230 & Overseas wholly-owned enterprises \\
\hline & & & 240 & Overseas shareholding limited companies \\
\hline \multirow[t]{4}{*}{4} & \multirow[t]{4}{*}{ Foreign-invested } & & 310 & Foreign joint ventures \\
\hline & & Joint ventures & 320 & Foreign cooperatives \\
\hline & & & 340 & Foreign shareholding limited companies \\
\hline & & Foreign MNCs & 330 & Foreign wholly-owned enterprises \\
\hline \multirow[t]{2}{*}{5} & \multirow{2}{*}{\multicolumn{2}{|c|}{ Shareholding }} & 159 & Other limited liability companies \\
\hline & & & 160 & Shareholding limited companies \\
\hline \multirow[t]{4}{*}{6} & \multirow{4}{*}{\multicolumn{2}{|c|}{ Private }} & 171 & Private wholly-owned enterprises \\
\hline & & & 172 & Private cooperatives enterprises \\
\hline & & & 173 & Private limited liability companies \\
\hline & & & 174 & Private shareholding companies \\
\hline \multirow[t]{3}{*}{7} & \multirow{3}{*}{\multicolumn{2}{|c|}{ Other domestic }} & 143 & State-collective jointly operated enterprises \\
\hline & & & 149 & Other jointly operated enterprises \\
\hline & & & 190 & Other enterprises \\
\hline
\end{tabular}

Table A.2: Number of firms (dataset after cleaning, and excluding firms' ownership belonging to category 7 Other domestic ownership type)

\begin{tabular}{lcccccccccc}
\hline Ownership types & 1998 & 1999 & 2000 & 2001 & 2002 & 2003 & 2004 & 2005 & 2006 & 2007 \\
\hline State-owned & 29171 & 31302 & 25955 & 21127 & 17893 & 13952 & 10245 & 9537 & 8083 & 5753 \\
Collective-owned & 41271 & 45231 & 40873 & 35738 & 32074 & 26870 & 19598 & 19495 & 16749 & 14115 \\
HMT-invested & 12082 & 14153 & 14807 & 16844 & 17896 & 19662 & 24253 & 26332 & 27964 & 26469 \\
Foreign-invested & 8595 & 9858 & 10661 & 12059 & 13500 & 16021 & 24521 & 27053 & 29599 & 28424 \\
Shareholding & 7867 & 11162 & 14259 & 19689 & 23292 & 26749 & 36281 & 41555 & 45956 & 43485 \\
Private-owned & 7981 & 12715 & 18055 & 31633 & 43318 & 57716 & 95746 & 112722 & 136294 & 128890 \\
Total & 106967 & 124421 & 124610 & 137090 & 147973 & 160970 & 210644 & 236694 & 264645 & 247136 \\
\hline
\end{tabular}

\section{A. Further descriptive statistics}

\section{B. Further quantile estimates by ownership types}


Table A.3: Total number of employees (dataset after cleaning, and excluding firms' ownership belonging to category 7 - Other domestic ownership type). Unit: millions

\begin{tabular}{lcccccccccc}
\hline Ownership types & 1998 & 1999 & 2000 & 2001 & 2001 & 2003 & 2004 & 2005 & 2006 & 2007 \\
\hline State-owned & 18.35 & 17.93 & 15.01 & 12.15 & 10.12 & 8.48 & 5.65 & 6.01 & 5.25 & 4.55 \\
Collective-owned & 10.14 & 10.40 & 9.19 & 7.50 & 6.67 & 5.53 & 3.39 & 3.45 & 2.95 & 2.62 \\
HMT-invested & 3.84 & 4.40 & 4.66 & 5.12 & 5.64 & 6.74 & 8.04 & 9.20 & 10.11 & 9.93 \\
Foreign-invested & 2.65 & 2.98 & 3.33 & 3.78 & 4.27 & 5.33 & 7.77 & 9.20 & 10.50 & 11.08 \\
Shareholding & 4.39 & 5.69 & 7.00 & 8.75 & 9.87 & 10.72 & 12.04 & 13.77 & 14.59 & 14.28 \\
Private-owned & 1.26 & 2.07 & 3.01 & 4.92 & 6.67 & 9.17 & 12.75 & 15.64 & 18.25 & 18.17 \\
Total & 40.63 & 43.46 & 42.20 & 42.22 & 43.25 & 45.98 & 49.63 & 57.28 & 61.65 & 60.63 \\
\hline
\end{tabular}

Figure A.1: Distribution of the number of firms in manufacturing across regions in China. Source: our elaboration on CMM.
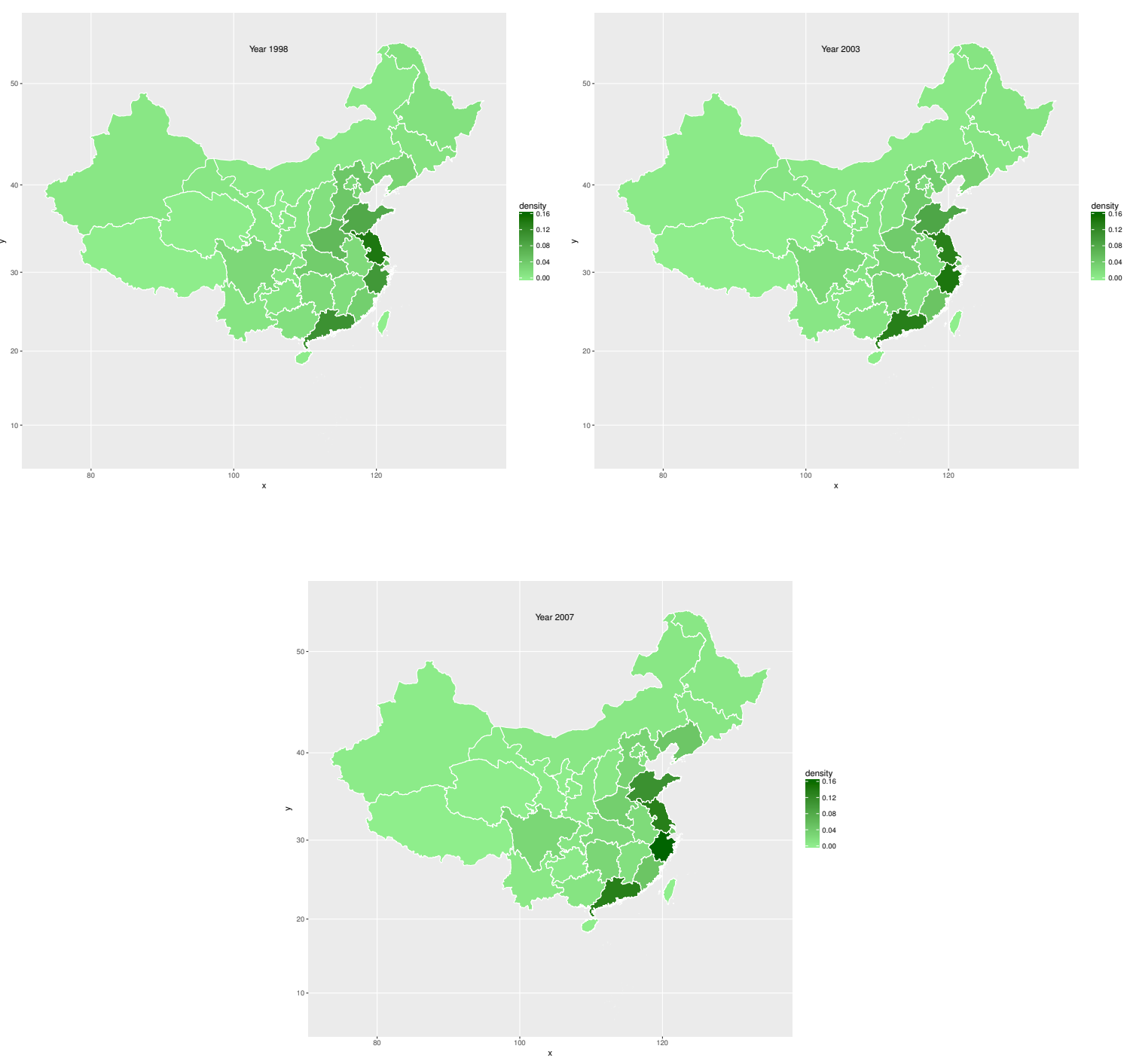
Table A.4: Elasticities by ownership types.

\begin{tabular}{lcccccccccc}
\hline Ownership types & 1999 & 2000 & 2001 & 2002 & 2003 & 2004 & 2005 & 2006 & 2007 & $1999-2007$ \\
\hline State-owned & 1.70 & 1.50 & -1.68 & 2.16 & 0.67 & 1.11 & 3.05 & 1.11 & 0.51 & 1.14 \\
Collective-owned & 0.96 & 1.41 & 0.06 & 0.72 & 0.61 & 26.20 & 0.61 & 1.23 & 1.15 & 0.92 \\
HMT-invested & 1.25 & 1.67 & -0.36 & 0.63 & 3.43 & 0.67 & 5.07 & 1.28 & 1.09 & 1.40 \\
Foreign-invested & 0.99 & 0.81 & -1.67 & 1.57 & 0.54 & 0.48 & 4.45 & 0.97 & 0.95 & 1.05 \\
Shareholding & 0.95 & 1.05 & 0.07 & 0.74 & 0.66 & 2.06 & 0.92 & 1.01 & 0.63 & 0.84 \\
Private-owned & 0.66 & 0.97 & 0.38 & 0.66 & 0.49 & 6.83 & 0.73 & 0.80 & 0.78 & 0.80 \\
\hline
\end{tabular}

Figure A.2: Wage/productivity 90-10 ratio by year, all manufacturing firms by six major ownership types.
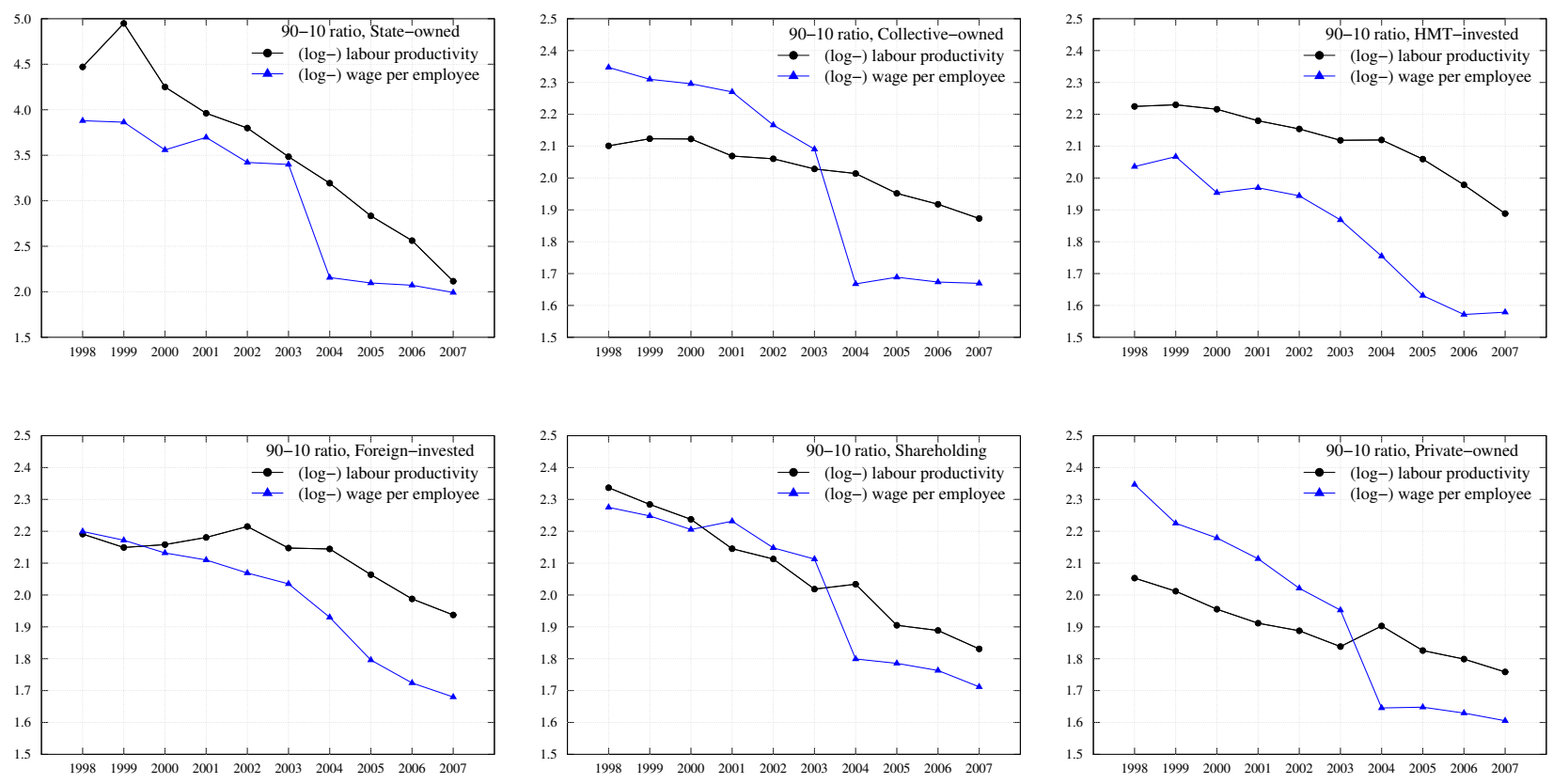

Note: equal weights. Source: our elaboration on CMM. 
Figure A.3: Wage at the top (90-50 ratio) versus bottom (50-10 ratio) of the distribution by year, all manufacturing firms by six major ownership types.
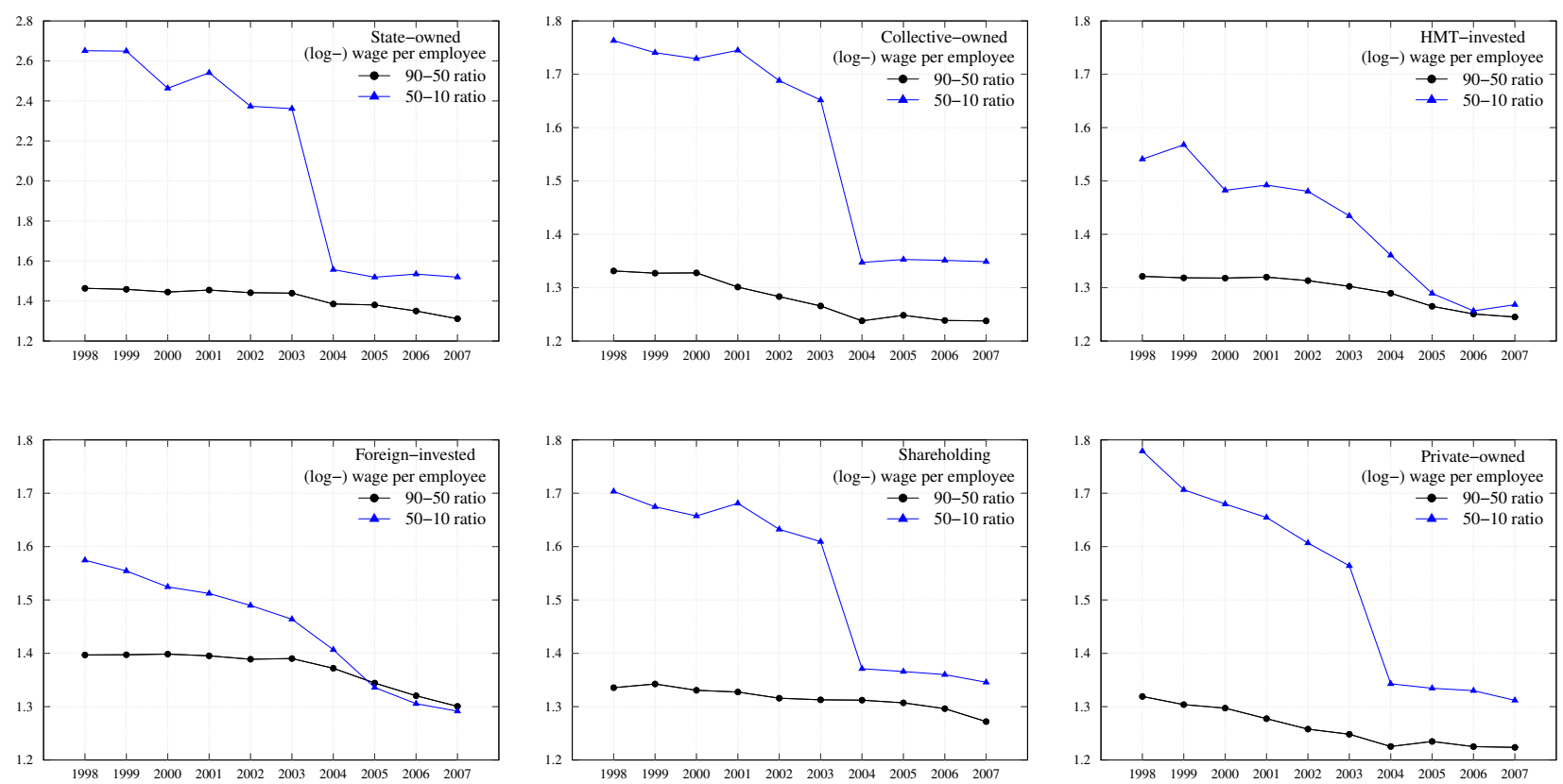

Note: equal weights. Source: our elaboration on CMM.

Figure A.4: Productivity at the top (90-50 ratio) versus bottom (50-10 ratio) of the distribution by year, all manufacturing firms by six major ownership types.
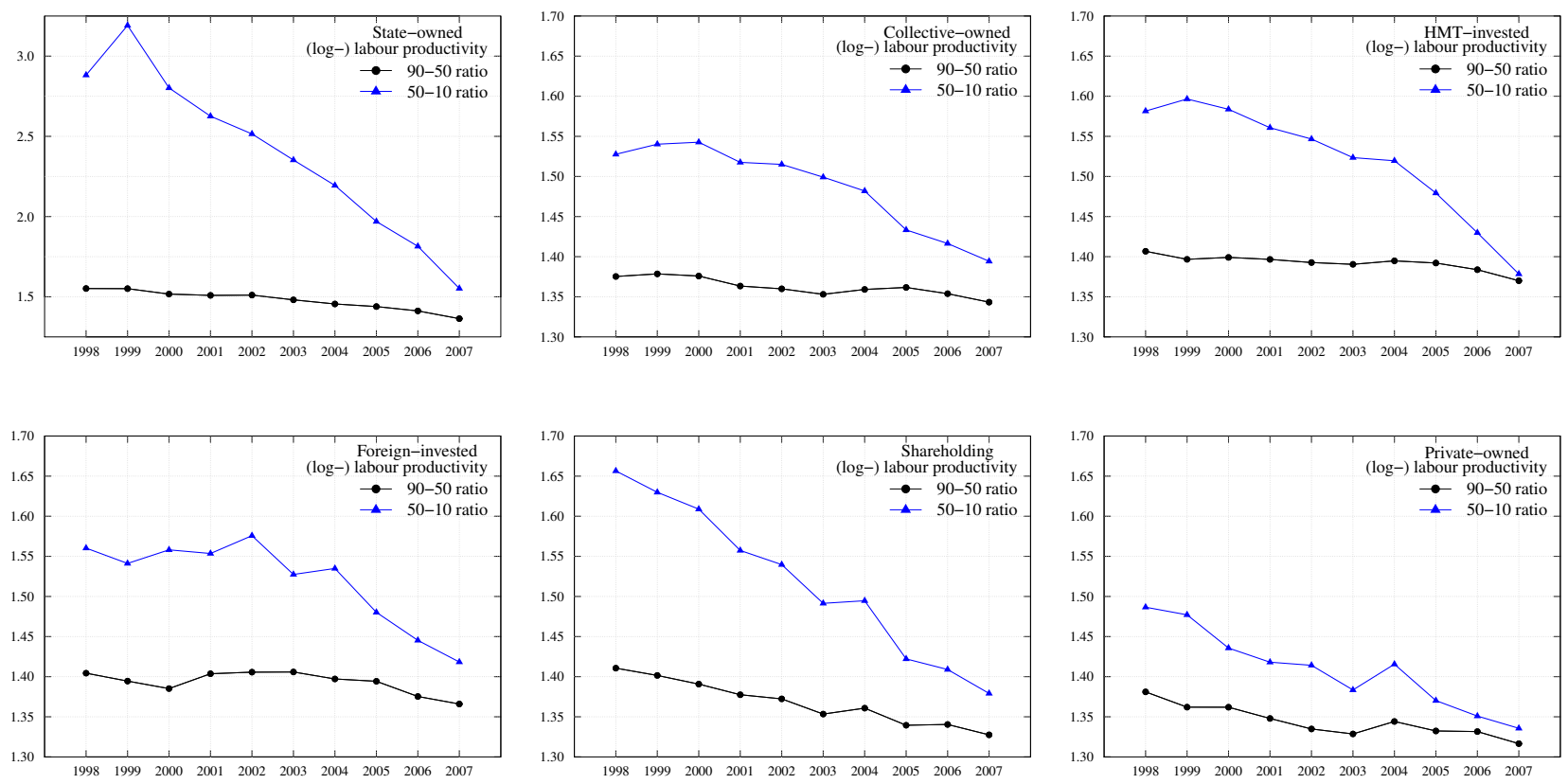

Note: equal weights. Source: our elaboration on CMM. 
Figure A.5: Share of within-sector wage [left] and labour productivity [right] dispersion by ownership types.
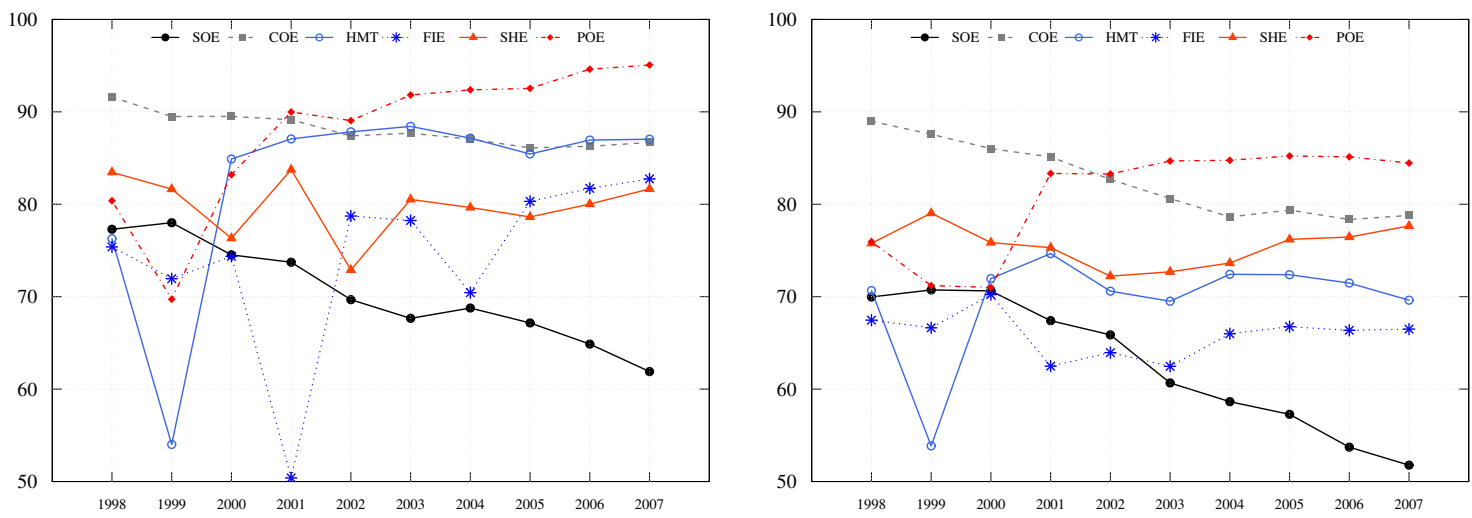

Note: pooling all firms in manufacturing sector, deviation from the 4-digit sectoral labour-weighted mean. Source: our elaboration on CMM.

Figure B.6: Model in level - CREM by ownership types.
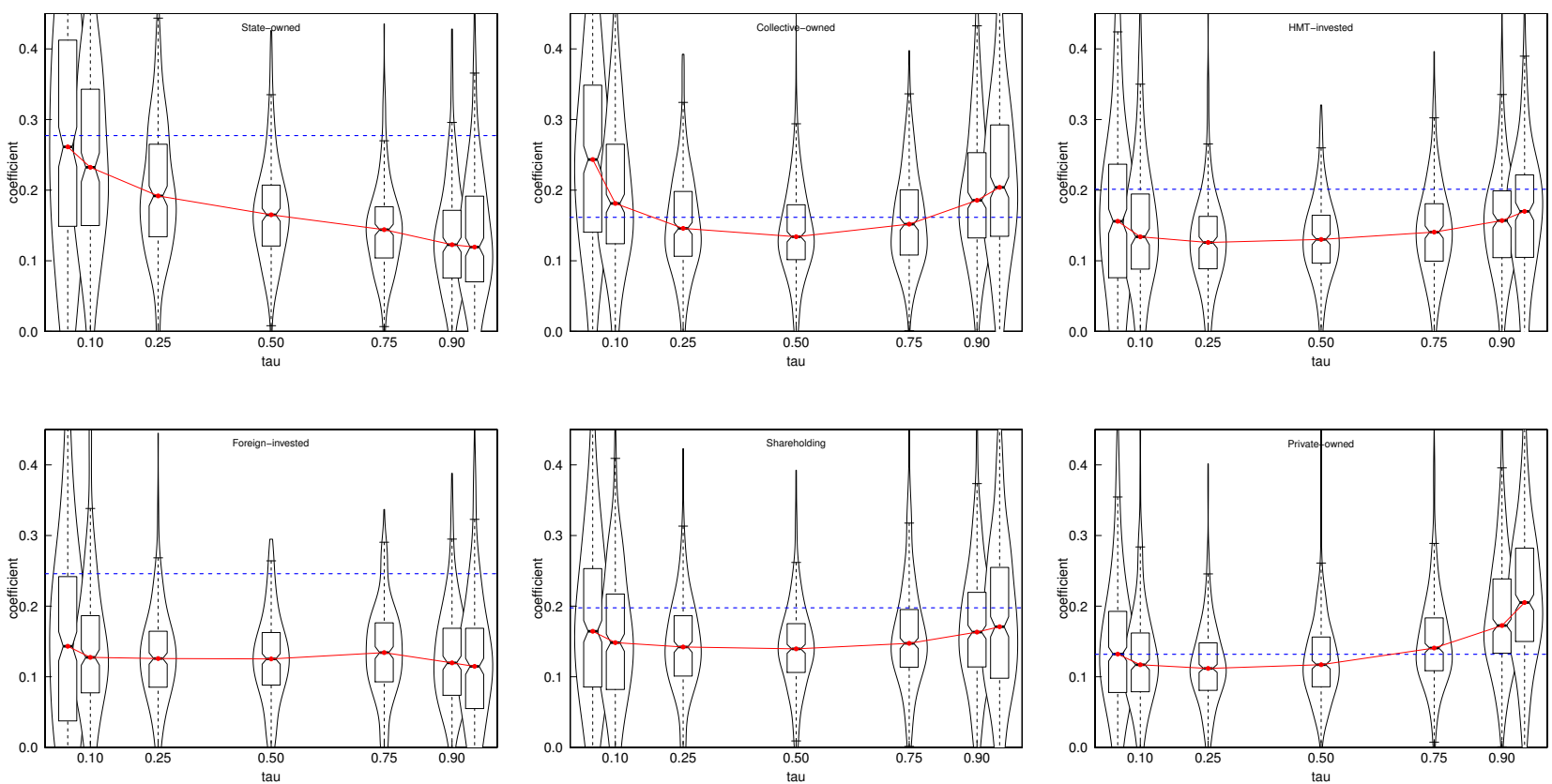

Distribution of quantile regression coefficients across four-digit sectors for each ownership type. Quantile regression estimation of equation (4). The coefficient on log- labour productivity reported for the $0.05,0.10,0.25$, $0.50,0.75,0.90$ and 0.95 quantiles. Note: keeping dataset with observations $>160$. The dashed line is the median of the distribution of OLS estimates. 
Figure B.7: Model in level - FE by ownership types.
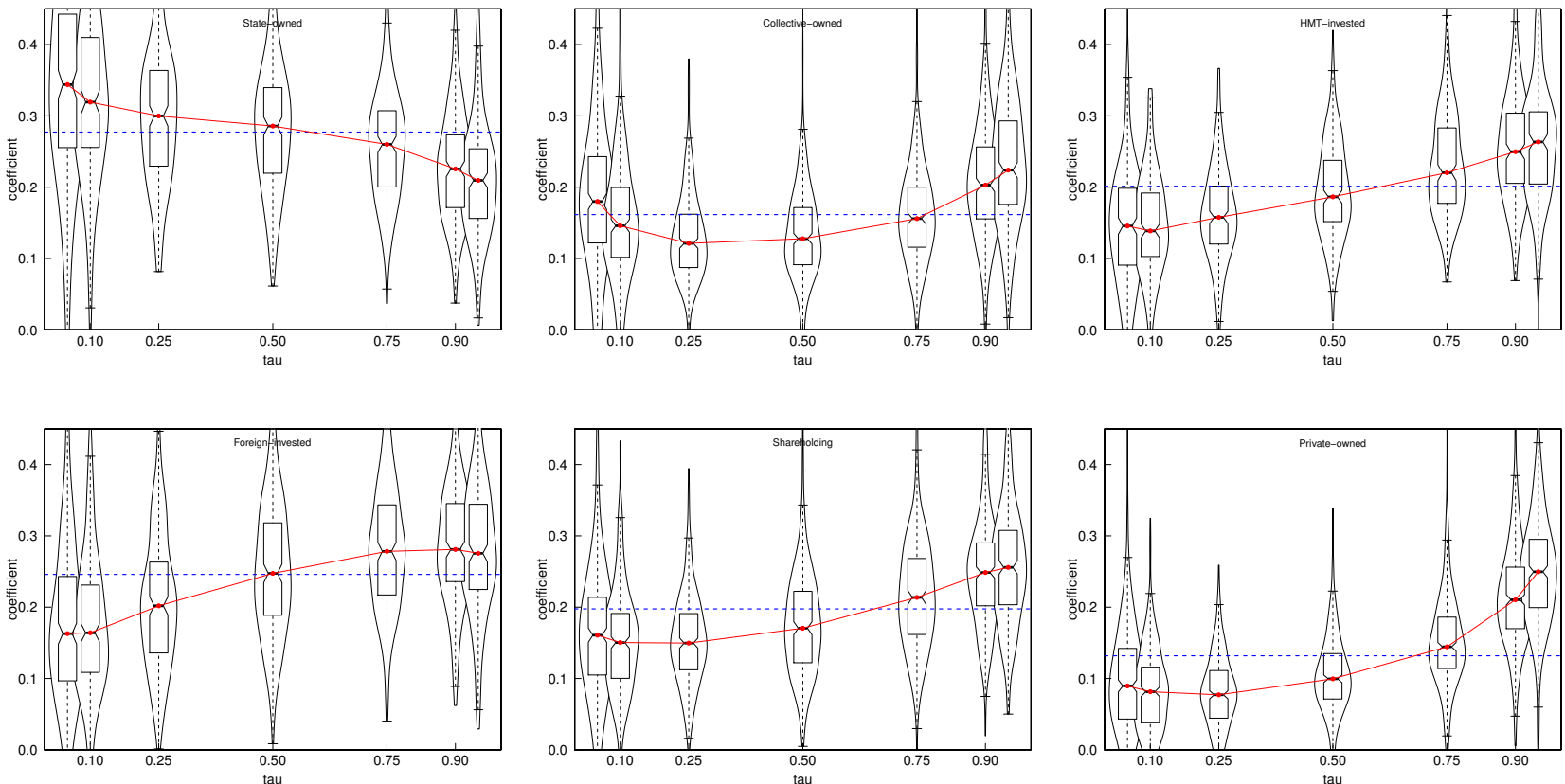

Distribution of quantile regression coefficients across four-digit sectors for each ownership type. Quantile regression estimation of equation (4). The coefficient on log- labour productivity reported for the $0.05,0.10,0.25$, $0.50,0.75,0.90$ and 0.95 quantiles. Note: keeping dataset with observations $>160$. The dashed line is the median of the distribution of OLS estimates.

Figure B.8: Quantile regression coefficients by ownership types.
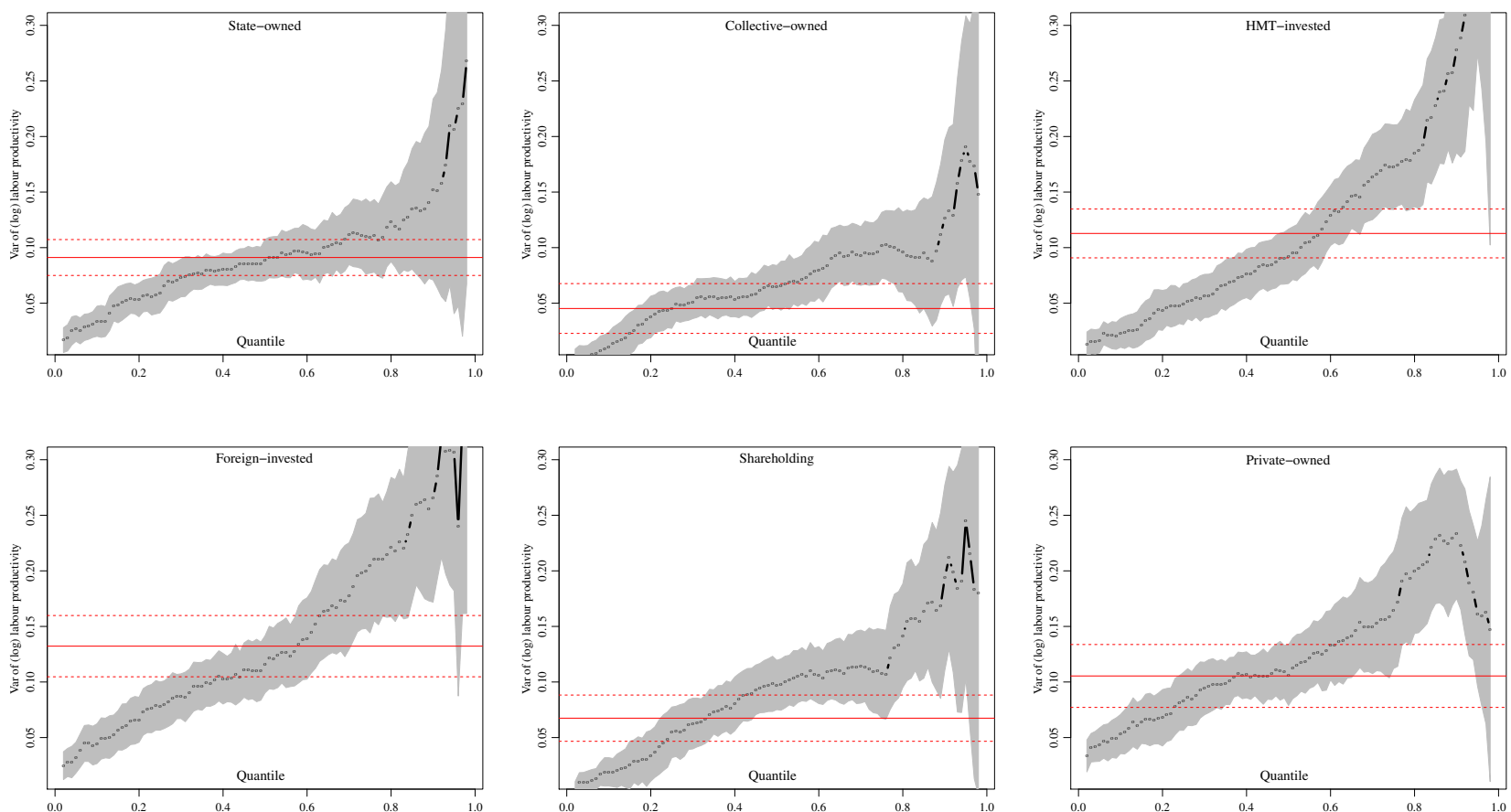

Quantile regression estimation of equation (15) pooling all 4-digit sectors, including 2-digit sectoral dummies. The solid line is the OLS estimate. Bootstrapped standard errors with $90 \%$ confidence band. 
Figure B.9: Quantile regression coefficients by ownership types.
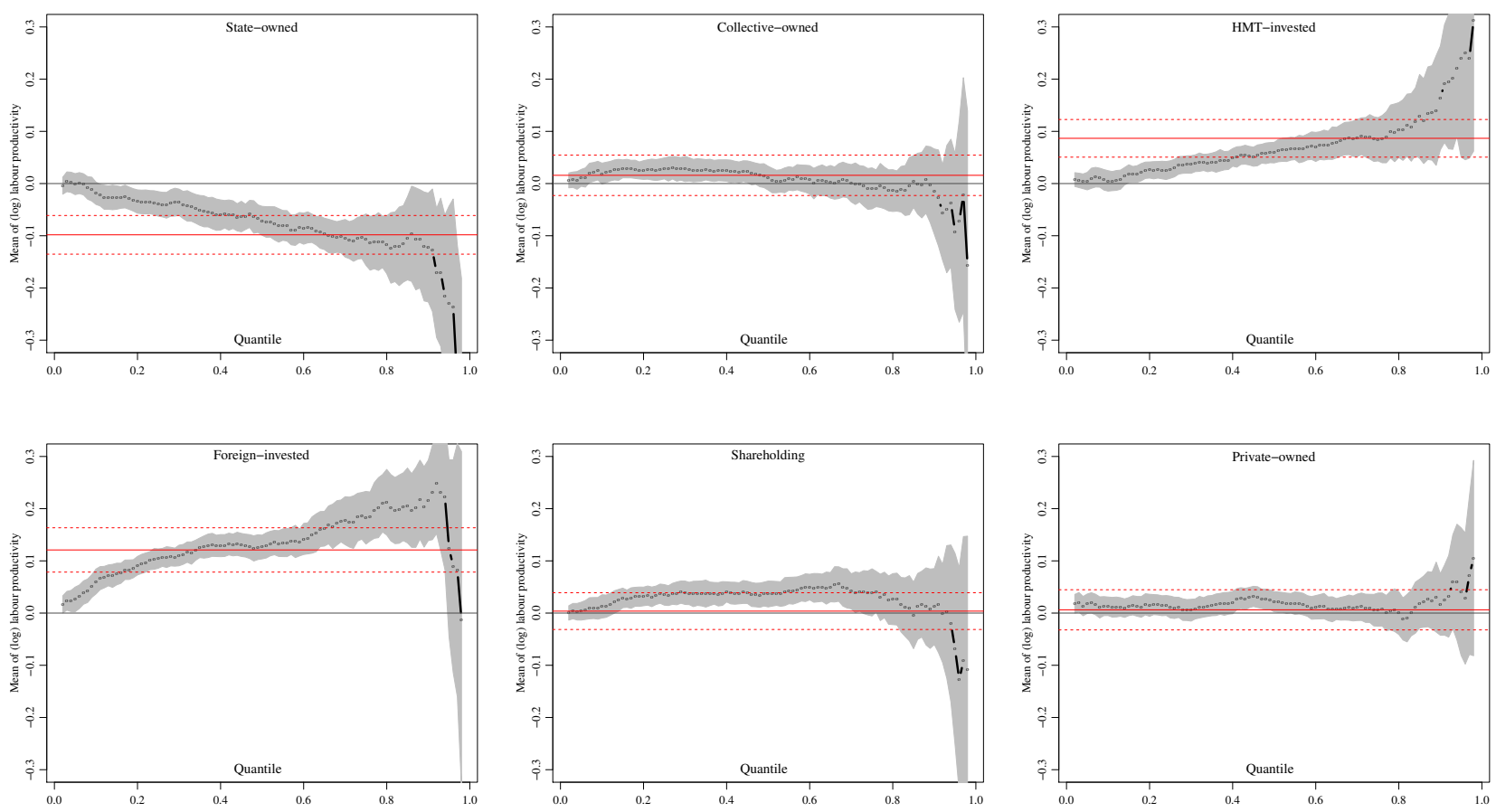

Quantile regression estimation of equation (16) pooling all 4-digit sectors, including 2-digit sectoral dummies. The solid line is the OLS estimate. Bootstrapped standard errors with $90 \%$ confidence band. 